UNIVERSIDADE DE SÃO PAULO

ESCOLA DE ENFERMAGEM

ELAINE REDA

INSTRUMENTO DE REGISTRO UTILIZADO NA AVALIAÇÃO EM SALA DE RECUPERAÇÃO PÓS-ANESTÉSICA:

IMPORTÂNCIA NA CONTINUIDADE DA ASSISTÊNCIA AO

PACIENTE CIRÚRGICO

São Paulo

2006 


\title{
ELAINE REDA
}

\section{INSTRUMENTO DE REGISTRO UTILIZADO NA AVALIAÇÃO EM SALA DE RECUPERAÇÃO PÓS-ANESTÉSICA: IMPORTÂNCIA NA CONTINUIDADE DA ASSISTÊNCIA AO PACIENTE CIRÚRGICO}

\author{
Dissertação apresentada à Escola de \\ Enfermagem da Universidade de São \\ Paulo, para obtenção do Título de Mestre \\ em Enfermagem
}

Orientadora:

Prof ${ }^{a}$. Dr. ${ }^{a}$ Aparecida de Cássia Giani Peniche 
Catalogação na publicação (CIP)

Biblioteca "Wanda de Aguiar Horta" da EEUSP

Reda, Elaine

Instrumento de registro utilizado na avaliação em sala de recuperação pós-anestésica: importância na continuidade da assistência ao paciente cirúrgico. / Elaine Reda. - São Paulo: E. Reda; 2006.

$103 \mathrm{p}$.

Dissertação (Mestrado) - Escola de Enfermagem da Universidade de São Paulo.

Orientadora: $\operatorname{Prof}^{a} \operatorname{Dr}^{\mathrm{a}}$ Aparecida de Cássia Giani Peniche

1. Anestesia (recuperação) 2. Registros de enfermagem 3. Enfermagem perioperatória. I. Título. 
Aos meus pais, Catarina de Toledo Piza Reda e José Pedro Reda, pelo incentivo, pelo carinho e pela confiança. Vocês me deram asas e me ensinaram a voar com responsabilidade. Obrigada por poder contar com vocês sempre. 
A professora e orientadora Dra. Aparecida de Cássia Giani Peniche, que dividiu seu conhecimento comigo e me acolheu neste trabalho. Obrigada pela confiança, pelo estimulo e pela forma responsável que conduziu as orientações. 


\section{Agradecimentos especiais}

Agradeço a Deus pela minha vida e por todas as

graças concebidas.

$\mathcal{A}$ minha irmã, Luciana Reda Ambrósio e seu marido, Gleifer Ferreira Ambrósio, pelo apoio e incentivo.

Ao meu noivo, Marcos Paulo da Silva, pela importante e dedicada contribuição para o término deste trabalho. Obrigada pela compreensão em todas as etapas desta trajetória e pelo apoio nos momentos difíceis.

Aos meus familiares, pelo apoio e carinho constantes, em especial a minha tia, Maria Aparecida de Toledo Martins, aos meus tios $\mathcal{N i l z a}$ e Washington Panzarin e Maria Iolanda e Clovis Schütz. 


\section{Agradecimentos}

À coordenadora do curso de enfermagem da Universidade São Francisco, Beatriz Helena de Araújo Verri, pelo apoío e oportunidade oferecida para que eu pudesse cursar o Mestrado.

$\mathcal{A}$ Banca Examinadora, os meus respeitosos agradecimentos e gratidão pela oportunidade de enxergarem o que se encontrava nebuloso ou ausente no meu trabalho, despertando-me para novos questionamentos.

Às professoras do curso de Pós-Graduação da Escola de Enfermagem da USP, pelos ensinamentos transmitidos durante esses anos.

Aos enfermeiros que participaram deste estudo, agradeço $o$ apoio e carinho com que me receberam em suas instituições e pelas valiosas informações que certamente contribuirão para melhorias no campo de ensino, pesquisa e assistência de enfermagem, colaborando no desenvolvimento de nossa profissão. 
À bibliotecária Nadir Aparecida Lopes pela revisão bibliográfica

À profa Valéria Silva Rosa de Almeida pela revisão da Língua Portuguesa e pela elaboração do abstract.

$\mathcal{A}$ todos que direta ou indiretamente contribuiram para a realização deste trabalho.

"Quando se diz obrigado, se dizem muitas coisas mais, que vêm de muito longe e de muito perto, de tão longe como a origem do ser humano, de tão perto como o secreto pulsar do coração." 
"Noão é o desafio com que nos deparamos que determina quem somos e o que estamos nos tornando, mas a maneira com que respondemos ao desafio". (autor desconhecido) 
Reda, E. Instrumento de registro utilizado na avaliação em sala de recuperação pósanestésica: importância na continuidade da assistência ao paciente cirúrgico [dissertação]. São Paulo (SP): Escola de Enfermagem da Universidade de São Paulo; 2006.

\section{RESUMO}

Este estudo tem como objetivo geral conhecer a avaliação, feita pelos enfermeiros das unidades pós-operatórias, a respeito da continuidade da assistência de enfermagem ao paciente cirúrgico. Como objetivos específicos, o seu propósito é identificar não só as dificuldades apresentadas pelos enfermeiros na obtenção dos dados clínicos referentes ao período de recuperação pós-anestésica como também indicar a melhor estratégia para obter os dados clínicos necessários para a continuidade da assistência de enfermagem ao paciente cirúrgico, após receber alta da sala de recuperação pós-anestésica, além de levantar os dados clínicos, referentes ao período de recuperação pós-anestésica, considerados necessários para o planejamento da assistência de enfermagem no período pós-operatório. A amostra foi constituída por enfermeiros, de duas instituições hospitalares identificadas por I e II, localizadas no interior do Estado de São Paulo, que assistem pacientes provenientes da recuperação pós-anestésica. Procedeu-se à coleta de dados, no período de julho a agosto de 2005, utilizando-se um formulário, a fim de contemplar o objetivo deste estudo. Os resultados mostraram que, no Hospital I, as dificuldades mais freqüentes, que interferem na obtenção dos dados clínicos do paciente referente ao período de recuperação pós-anestésica, foram, com $22(84,62 \%)$ relatos cada: ausência do instrumento no prontuário e ausência da passagem de plantão por telefone, seguidas da ausência de informações necessárias no instrumento 19 (73,08\%); preenchimento incompleto do instrumento $12(46,15 \%)$ e passagem incompleta de plantão por telefone $2(7,69 \%)$. No Hospital II destacaram-se: preenchimento incompleto do instrumento $25(75,76 \%)$, seguidas da ausência de informações necessárias no instrumento 19 (57,58\%). E com 18 (54,55\%) relatos cada: ausência do instrumento no prontuário; ausência da passagem de plantão por telefone e passagem incompleta de plantão por telefone. No Hospital I, a melhor estratégia para se obter informações do paciente com alta da recuperação pós-anestésica foi um instrumento de registro associado à passagem de plantão por telefone 17 (65,38\%), enquanto que no Hospital II a maioria, 20 enfermeiros $(60,61 \%)$, agregou os diversos meios de se obter informações. Dentre os dados clínicos considerados necessários, pelos enfermeiros que não consultavam esse instrumento, no Hospital I, destacaram-se as características dos curativos e drenos, nível de consciência, controle das sondas, sinais vitais e acesso venoso. No Hospital II destacaram-se sinais vitais e características dos drenos, seguidos de curativos, saturação de oxigênio e exame físico. Quanto aos enfermeiros que o consultaram, 8 (30,77\%) do Hospital I e 21 $(63,64 \%)$ do Hospital II, foram de opinião que os dados clínicos presentes neste instrumento eram extremamente importantes, com exceção dos parâmetros referentes à temperatura e pulso que, no Hospital I, apresentaram diferenças de opinião quanto ao nível de importância (extremamente importante e muito importante). Sendo assim, observa-se que, nos dois hospitais estudados, o instrumento de registro, meio 
concreto de comunicação, auxilia no planejamento, promove a continuidade, é um indicador de qualidade e um meio de documentar o cuidado com o paciente.

Palavras-chave: anestesia (recuperação), registros de enfermagem, enfermagem perioperatória. 
Reda, E. Instrument of register used in the valuation of a post anesthetic recovery room: importance in continuing to assist the chirurgical patient [dissertação]. São Paulo (SP): Escola de Enfermagem da Universidade de São Paulo; 2006.

\section{ABSTRACT}

This study has the main objective to know the valuation, done by nurses in the postoperator units, to continue giving nursing assistance to the chirurgical patient. As specific objectives it has the purpose to identify not only the difficulties presented by the nurses to obtain the clinical data referring to the post-anesthetic period but also to indicate the best strategy to get the clinical data necessary to continue the nursing assistance to the chirurgical patient after receiving discharge of the post-anesthetic recovery room, besides uplifting clinical data, referring to the post-anesthetic recovery period, considered necessary to plan the nursing assistance in the postoperator period. The sample was constituted by nurses in two hospitals identified by I and II, located in the State of São Paulo inland, Brazil which assist patients deriving from post-anesthetic recovery. During July to August 2005, the data collection was conducted, using a formulary in order to contemplate the objective of this study. The results showed that, at the Hospital I, the most frequent difficulties, that interfere in the acquisition of the patient's clinical data referred to the post-anesthetic period were, with $22(85,62 \%)$ reports each: absence of the instrument in the formulary and also absence of the duty passage by telephone, followed by the absence of information necessary in the instrument 19 (73,08\%); incomplete fulfilling of the instrument $12(46,15 \%)$ and incomplete duty passage by telephone $2(7,69 \%)$. It was distinguished at the Hospital II: incomplete fulfilling of the instrument $25(75,76 \%)$, followed by absence of information necessary in the instrument $19(57,58 \%)$. And with 18 (54,55\%) reports each: absence of the instrument in the formulary; absence in the duty passage by telephone and incomplete duty passage by telephone. At the Hospital I, the best strategy to obtain patient's information with discharge from the post-anesthetic recovery was an instrument of register associated to the duty passage by telephone $17(65,38 \%)$, while at the Hospital II the majority, 20 nurses $(60,61 \%)$, added diverse ways to obtain information. Among the clinical data considered necessary by the nurses who did not consult this instrument, at the Hospital I, the characteristics of the bandaging and drains; level of consciousness; control of probes; vital signals and vein access were distinguished. At the Hospital II: vital signals and characteristics of the drains, followed by bandaging; saturation of oxygen and physical exam. As to the nurses who have consulted it, $8(30,77 \%)$ at the Hospital I and $21(63,64 \%)$ at the Hospital II, they had the opinion that the clinical data presented in this instrument were extremely important, with exception of the parameters referred to temperature and pulse that, at the Hospital I, presented differences of opinion as to the level of importance (extremely important and very important). So, it was observed that in the two hospitals the instrument of register, a concrete way of communication, helps the planning, promotes the continuity, it is a quality indicator and a way to prove the care with the patient.

Key-words: anesthesia (recovery), nursing registers, perioperator nursing. 


\section{LISTA DE ABREVIATURAS}

CC - Centro Cirúrgico

COREN - Conselho Regional de Enfermagem

Inst. - Instrumento

MAE - Metodologia da Assistência de Enfermagem

MBAH - Manual Brasileiro de Acreditação Hospitalar

P - Pulso

PA - Pressão Arterial

PAM - Pressão Arterial Média

PE - Processo de Enfermagem

PIC - Pressão Intracraniana

PSF - Programa Saúde da Família

PVC - Pressão Venosa Central

R - Respiração

RPA - Recuperação Pós-Anestésica

SAE - Sistema de Assistência de Enfermagem

SAEP - Sistema de Assistência de Enfermagem no Período Pós-Operatório

$\mathbf{S a O}_{2}$ - Saturação de Oxigênio

SNC - Sistema Nervoso Central 
SOBECC - Sociedade Brasileira de Enfermeiros de Centro Cirúrgico, Centro de Material e Recuperação Anestésica

SRPA - Sala de Recuperação Pós-Anestésica

SUS - Sistema Único de Saúde

$\mathbf{T}^{\mathbf{o}}$ - Temperatura

USP - Universidade de São Paulo

UTI - Unidade de Terapia Intensiva 


\section{LISTA DE TABELAS}

TABELA 1 - Caracterização da amostra estudada segundo setores/cargos envolvidos, tempo de trabalho, jornada de trabalho, tempo de formação e cursos de especialização ou outros. São Paulo 2005

TABELA 2 - Distribuição das dificuldades, apresentadas pelos enfermeiros, na obtenção dos dados clínicos do paciente, referente ao período de recuperação pós-anestésica. São Paulo - 2005.

TABELA 3 - Distribuição das estratégias, utilizadas pelos enfermeiros, para se obter informações do paciente com alta da recuperação pós-anestésica. São Paulo - 2005 50

TABELA 4 - Distribuição da avaliação, feita pelos enfermeiros, sobre o instrumento de registro da recuperação pós-anestésica. São Paulo - 2005 52

TABELA 5 - Distribuição dos enfermeiros segundo consulta ao instrumento de registro da recuperação pós-anestésica. São Paulo - 2005.

TABELA 6 - Distribuição da importância dos dados clínicos, segundo avaliação dos enfermeiros, que consultam o instrumento de registro da recuperação pós-anestésica. São Paulo - 2005

TABELA 7 - Distribuição dos motivos pelos quais o instrumento de registro da recuperação pós-anestésica não é consultado. São Paulo 2005 56 


\section{LISTA DE QUADROS}

QUADRO 1 - Distribuição dos dados clínicos, utilizados pelos enfermeiros, no período pós-operatório, que não se utilizam do instrumento de registro da recuperação pós-anestésica para dar continuidade à assistência ao paciente cirúrgico. São Paulo - 2005 57 


\section{SUMÁRIO}

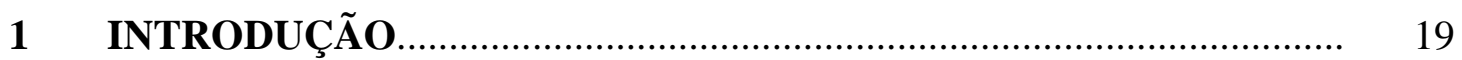

1.1 Documentação do cuidado de enfermagem................................................. 20

1.2 Sistema de assistência de enfermagem no período perioperatório (SAEP).. 25

1.3 Assistência de enfermagem no período de recuperação pós-anestésica....... 30

1.4 Comunicação e continuidade do cuidado..................................................... 33

2 OBJETIVOS ......................................................................... 39

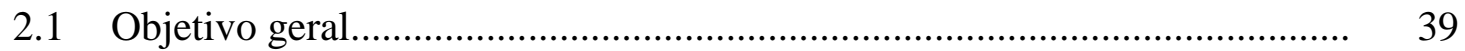

2.2 Objetivos específicos.......................................................... 39

3 MATERIAL E MÉTODO..................................................... 41

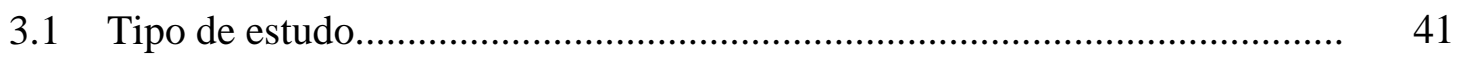

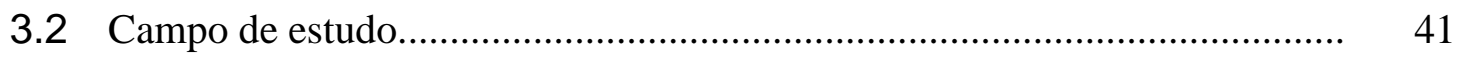

3.3 População de estudo............................................................................. 41

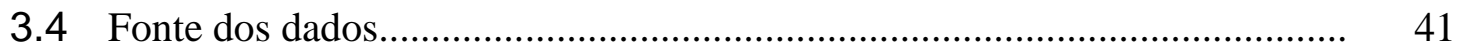

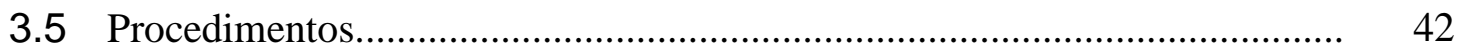

3.5.1 Procedimento ético-legal.................................................................... 42

3.5.2 Procedimento de coleta de dados............................................................ 43

3.5.3 Procedimento de análise dos dados........................................................ 43

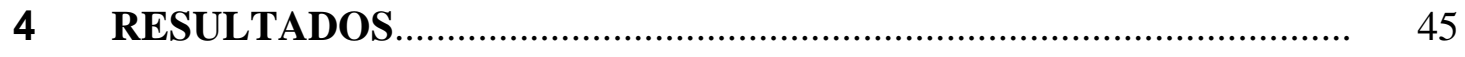

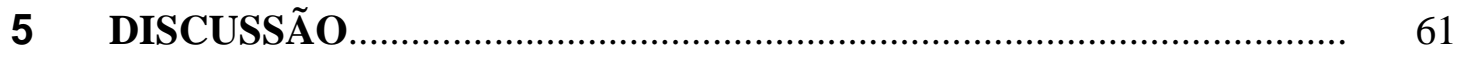

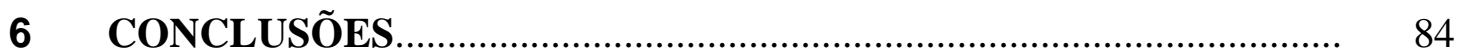

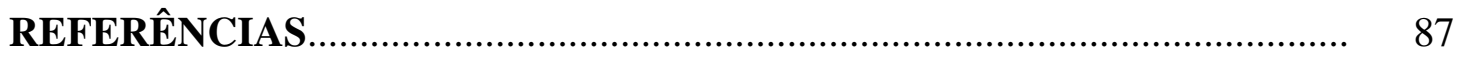

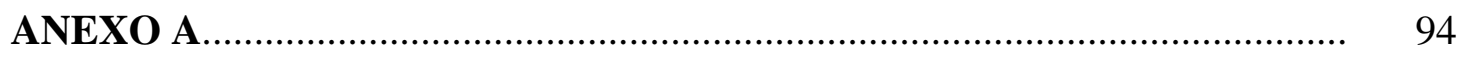

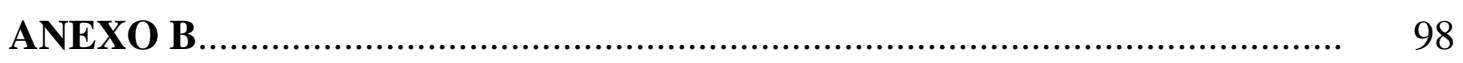

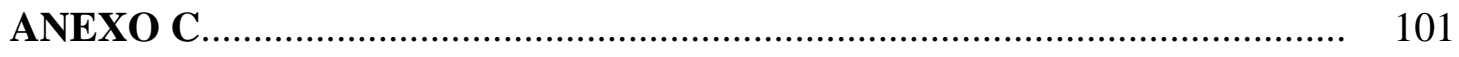

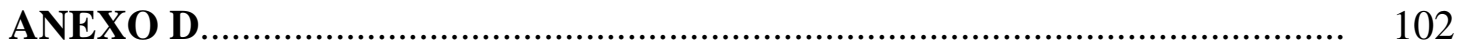




$$
\text { D }
$$




\section{INTRODUÇÃO}

Desde janeiro de 2000, o Sistema de Assistência de Enfermagem (SAE) tornou-se obrigatório em todo o Estado de São Paulo, de acordo com a Decisão COREN-SP/ DIR/ 008/99. Esta obrigatoriedade fica evidente quando se detecta que $65 \%$ das instituições hospitalares não sabem como implantá-lo ${ }^{(1)}$.

O SAE é um processo que objetiva a promoção, manutenção e recuperação da saúde do cliente e da comunidade, devendo ser desenvolvido pelo enfermeiro com base nos conhecimentos técnicos e científicos inerentes à profissão. Para sua aplicação, faz-se necessária a adoção de uma ou mais teorias de enfermagem que fundamentarão a prática da assistência de enfermagem ${ }^{(2)}$. A sua implementação exige do enfermeiro interesse em conhecer o paciente como um indivíduo, utilizando para isso seus conhecimentos e habilidades, além de orientação e treinamento da equipe de enfermagem para a execução das ações sistematizadas ${ }^{(3)}$.

Porém, observa-se uma dificuldade natural na operacionalização desta sistematização nas diversas unidades de uma instituição, e esta se acentua em terapia intensiva e centro cirúrgico pelas próprias características destas unidades.

Especificamente, no centro cirúrgico, observa-se que a ausência de dados, referentes à assistência perioperatória, dificulta a continuidade do cuidado prestado ao paciente cirúrgico no período pós-operatório, tanto imediato como tardio.

Acredita-se que, com a ausência de informações nos prontuários, aumenta-se a lacuna entre período perioperatório e as unidades de internação, com prejuízos para a equipe de enfermagem e, principalmente, para o paciente.

O registro correto, em um instrumento, dos parâmetros clínicos do paciente em recuperação pós-anestésica parece ser uma forma que auxilia o 
preenchimento deste vazio existente. Segundo Padovani, Gatto, Peniche ${ }^{(4)}$, em estudo realizado para avaliação dos dados oferecidos por um instrumento de registro utilizado na unidade de recuperação pós-anestésica, verificou-se que estes subsidiaram o planejamento da assistência de enfermagem no período pós-operatório imediato. Evidenciou-se, também, a falta de entrosamento entre as equipes de enfermagem das unidades envolvidas com a assistência ao paciente cirúrgico, no período pós-operatório, isto é, entre as enfermeiras das unidades de recuperação pósanestésica e das clínicas cirúrgicas, uma vez que, das 40 enfermeiras entrevistadas, 21 delas não utilizavam nenhum meio de comunicação para obter informações sobre as condições clínicas dos pacientes vindos da recuperação pós-anestésica.

Sendo assim, a obrigatoriedade legal de inserção do processo de enfermagem na assistência ao paciente cirúrgico coincide com a seriedade com que o mesmo deve ser avaliado, ou seja, como um paciente crítico, razão pela qual a equipe de enfermagem precisa dispor de informações corretas e pertinentes do período perioperatório e, mais especificamente, da assistência de enfermagem prestada ao paciente na unidade de recuperação pós-anestésica.

Diante do exposto, surgiu a necessidade da realização desta pesquisa com a finalidade de identificar qual a apreciação dos enfermeiros que assistem pacientes provenientes da sala de recuperação pós-anestésica, quanto ao instrumento de registro, utilizado nesse setor, na continuidade da assistência de enfermagem ao paciente cirúrgico e quanto aos dados clínicos necessários para o planejamento dessa assistência.

\subsection{Documentação do cuidado de enfermagem}


A profissão Enfermagem vivencia um grande desafio na construção e organização do conhecimento sobre o qual alicerça e direciona a sua prática assistencial. Faz parte desse desafio o desenvolvimento de um processo de trabalho para concretizar a proposta de promover, manter ou restaurar o nível de saúde do cliente. Assim surge a Metodologia da Assistência de Enfermagem (MAE): um instrumento metodológico e sistemático de prestação de assistência de enfermagem individualizada, centrado nas respostas humanas à uma alteração atual ou potencial de saúde ${ }^{(5)}$.

A metodologia da assistência foi introduzida no Brasil, na década de 70, pelos trabalhos de $\operatorname{Horta}^{(6)}$. Nas duas décadas subseqüientes, poucas experiências foram relatadas sobre a utilização dessa metodologia na prática da assistência de enfermagem. Esse tema resurgiu na literatura brasileira a partir do final da década de 80. Mas somente na década de 90, a metodologia da assistência centrada nos moldes operacionais do diagnóstico de enfermagem (etapa central da MAE) ganha um forte impulso no seu desenvolvimento e organização.

Todas as etapas da metodologia da assistência de enfermagem, desde a coleta de dados, o diagnóstico de enfermagem, o planejamento, sua implementação e avaliação, são contempladas na literatura de enfermagem.

Essa metodologia tem recebido diferentes denominações como: Processo de Enfermagem (PE); Sistematização da Assistência de Enfermagem (SAE); ou Metodologia da Assistência de Enfermagem (MAE) ${ }^{(5)}$.

Mussi et al. ${ }^{(7)}$ e Sena et al. ${ }^{(8)}$, ressaltam que cada modelo teórico aplicado à prática de enfermagem pode adotar arcabouços conceituais diferentes no 
"processamento" do cuidar, com nomenclaturas distintas daquelas que têm sido utilizadas tradicionalmente pela MAE.

Nas três últimas décadas, verificou-se um reconhecimento da importância e da necessidade de se buscar uma enfermagem sistematizada, legitimando a MAE, como marco teórico da prática de enfermagem. A metodologia é fundamental para sistematizar as ações de enfermagem em qualquer cenário de cuidado à saúde ou educacional, seja hospitalar ou ambulatorial, e no contexto das diversas filosofias de enfermagem $^{(9,10)}$.

Apesar de difícil, problemática e muitas vezes polêmica, a implantação da MAE é mundialmente considerada uma grande conquista, como um instrumento de trabalho para nortear a prática da enfermagem. De fundamental importância na organização do conteúdo do cuidar, ela favorece o direcionamento das ações e seu controle, subsidia e facilita a avaliação das atividades inerentes ao cuidar, viabilizando e tornando concretos os resultados dessa assistência ${ }^{(7,11)}$.

A utilização do processo de enfermagem como método científico no cuidado de enfermagem ao paciente, não só é requisito essencial à segurança do indivíduo e à eficiência deste cuidado, como também é conseqüente à necessidade da enfermagem em documentar e avaliar os serviços que ela $\operatorname{presta}^{(12)}$.

$\mathrm{O}$ processo de enfermagem é um conceito aceito, nacional e internacionalmente, para provimento de cuidado qualificado, devendo ser uma parte integrante da enfermagem atual ${ }^{(13)}$. Segundo Little e Carnevalli citados por Castellanos $^{(14)}$, prestar cuidado de enfermagem planejado e individualizado numa base sistemática é aceito teoricamente. Porém, observamos na realidade que, 
sistemas efetivos de planejamento de cuidados, incorporados em padrões para serviços de enfermagem organizados, aparecem pouco na prática.

Segundo Meeker e Rothroch ${ }^{(15)}$, o foco do processo de enfermagem está centralizado no paciente e as intervenções de enfermagem prescritas são aquelas que atendem as necessidades do mesmo. Desta forma, se visto isoladamente, o processo de enfermagem torna-se nada mais que um roteiro de preparação de equipamentos e registros em documentos. Se, ao contrário, visto enquanto uma estratégia para o cuidado, torna-se um processo científico, contínuo e que determina um alto nível de assistência.

Existe uma grande diferença, como bem frisa Christman ${ }^{(16)}$, na qualidade do cuidado, que deriva da utilização de conhecimentos e habilidades pautados em um processo científico, comparado com o cuidado pouco criativo que geralmente é o resultado do comportamento automático, tarefeiro, que se pode denominar de "prática reflexa", ou seja, "o processo de enfermagem é uma atividade comportamental e intelectual claramente definida"(17). "É uma maneira ordenada e sistemática de determinar os problemas do cliente (isto é, avaliando e atingindo um diagnóstico) elaborando e executando planos para resolvê-los, além de avaliar a efetividade destes planos na resolução dos problemas identificados"(18). "Uma dinâmica das ações sistematizadas e interrelacionadas que visa à assistência ao indivíduo, família e comunidade"(13). É ainda:

um método sistemático de prestação de cuidados humanizados, que enfoca a obtenção de resultados desejados de uma maneira produtiva, sendo desenvolvido em cinco passos. São eles: investigação, diagnóstico, planejamento, implementação e avaliação. Pautado na crença de que à medida que planejamos e proporcionamos cuidados, devemos considerar 
exclusivamente os interesses, ideais e desejos do consumidor do atendimento de saúde (a pessoa, a família e a comunidade) ${ }^{(18)}$.

Segundo Miranda ${ }^{(19)}$, o processo de enfermagem, seguramente, atende a quatro importantes objetivos:

- Promove a comunicação entre os diversos profissionais.

- Direciona o cuidado de enfermagem e a respectiva documentação.

- Cria um registro que pode ser usado em avaliações, pesquisas e processos éticos, administrativos, civis ou criminais.

- Fornece a documentação sobre necessidades de atendimentos de saúde que servirá para promover políticas públicas.

Por outro lado, os estudos e a experiência sobre as anotações de enfermagem mostram que, quase sempre, estas se apresentam insuficientes, rudimentares e que os dados relevantes sobre o paciente não têm sido registrados, constatando-se, assim, que as anotações não vêm cumprindo seu papel no processo de assistência a que o cliente tem direito ${ }^{(20)}$.

Para Teixeira ${ }^{(21)}$, o prontuário do paciente é definido como o documento único constituído de um conjunto de informações, sinais e imagens registradas, geradas a partir de fatos, acontecimentos e situações sobre a saúde do paciente e a assistência a ele prestada, de caráter legal, sigiloso e científico, que possibilita a comunicação entre membros da equipe multiprofissional e a continuidade da assistência prestada ao indivíduo, o qual, infelizmente, no dia-a-dia, é visto como uma verdadeira obra-prima de desinformação, de descaso e de descuido.

Como bem alertam Wiggins e Carter citados por Castellanos $^{(14)}$ :

a documentação e avaliação dos serviços prestados pelo enfermeiro é requisito essencial para a enfermagem como profissão; se desejarmos 
reter a responsabilidade das ações de enfermagem nós precisamos ser capazes de apresentar nossos padrões de cuidado ao paciente de uma maneira formal e providenciar instrumentos para avaliar o cuidado à luz destes padrões; sem isso nós não poderemos ser o verdadeiro profissional liberal.

O cuidado não documentado significa que não foi realizado, portanto a necessidade de um registro preciso da assistência de enfermagem. Uma descrição do paciente, os diagnósticos de enfermagem, o cuidado prestado pela enfermagem, e a resposta do paciente aos cuidados (avaliação) devem ser incluídos no relatório do paciente. Os impressos para esta documentação podem incluir tanto os protocolos estabelecidos como as intervenções; o espaço deve ser garantido para escrever as intervenções que são únicas para cada paciente. A documentação deve requerer pouco tempo para o preenchimento dos dados do paciente, ser específica para o serviço perioperatório, e oferecer continuidade nas unidades envolvidas com a assistência ao paciente cirúrgico (centro cirúrgico, recuperação pós-anestésica e unidades de clínicas cirúrgicas) ${ }^{(15)}$.

\subsection{Sistema de Assistência de Enfermagem no Período Perioperatório (SAEP)}

Segundo Jouclas ${ }^{(22)}$, o que define o conhecimento não é aquilo que cada categoria sabe fazer, mas o próprio desenvolvimento de uma prática de enfermagem. Essa prática, portanto, está fundamentada no modelo conceitual de enfermagem em centro cirúrgico e que deve nortear um método de assistência.

Autoras como Brunner e Suddath ${ }^{(23)}$ fazem menção à assistência de enfermagem em centro cirúrgico abrangendo as fases pré-operatória, intraoperatória e pós-operatória. Cada uma dessas fases implica, segundo as autoras acima, em 
comportamentos e atividades que o enfermeiro realiza através da aplicação do processo de enfermagem.

Vários autores ressaltam a importância da sistematização da assistência de enfermagem perioperatória. A pesquisa retrospectiva realizada mostra que esta abordagem teve início em 1973 com autores internacionais ${ }^{(24)}$.

No Brasil, Jouclas ${ }^{(22)}$ refere que a primeira enfermeira a propor a sistematização do processo de enfermagem no cuidado dos pacientes na unidade de centro cirúrgico foi Castellanos, tendo como base a Teoria das Necessidades Básicas de Horta. Tempos depois, Castellanos e Jouclas ${ }^{(25)}$ propuseram um "Modelo Conceitual Filosófico" de assistência de enfermagem perioperatória (SAEP), abrangendo os conceitos da assistência holística, continuada, participativa, individualizada, documentada e avaliada. A operacionalização deste modelo se desenvolve nos períodos: pré-operatório, intraoperatório, recuperação pós-anestésica e pós-operatório.

No período pré-operatório é realizada uma avaliação tendo como estratégia a visita pré-operatória. É realizada a entrevista com o paciente a ser operado, a consulta ao prontuário e ao enfermeiro da unidade de internação.

Após a identificação dos problemas realiza-se o planejamento da assistência de enfermagem seguido da evolução e da prescrição de enfermagem para o transoperatório.

A implantação desta prescrição é realizada já na fase transoperatória que termina com a evolução de enfermagem e prescrição para o período de recuperação pós-anestésica. Neste período, nova avaliação é realizada, seguida de prescrição e implementação de cuidados. Ao término desta fase, o paciente deve seguir com uma 
evolução de alta para sua unidade de origem, onde após 24 e 48 horas será realizada a avaliação pós-operatória (visita pós-operatória de enfermagem)

Os objetivos do SAEP são ajudar o paciente e sua família a compreender seu problema de saúde; a preparar-se para o ato anestésico-cirúrgico proposto e suas conseqüências; a utilizar seus mecanismos de defesa fisiológicos e psicológicos, durante este período. Além de colaborar na diminuição dos riscos inerentes ao ambiente específico do centro cirúrgico e da sala de recuperação pós-anestésica, através da utilização de materiais e equipamentos necessários ao desenvolvimento dos procedimentos anestésicos-cirúrgicos, bem como na execução destes procedimentos pela previsão, provisão e controle dos recursos humanos em qualidade e quantidade necessários.

Salzano ${ }^{(26)}$, afirma que a enfermeira do centro cirúrgico não tem somente a responsabilidade para com seus pacientes no transoperatório, mas para com as outras enfermeiras, a fim de promover um cuidado de enfermagem que seja coordenado e contínuo.

Entretanto, na nossa realidade o SAEP é, na maioria das vezes, implementado em algumas fases e por um grupo restrito de enfermeiros e este fato é constatado indiretamente quando Silva ${ }^{(27)}$, em uma pesquisa, detectou que apenas três, ou seja, $10 \%$ dos enfermeiros entrevistados estavam realizando a visita préoperatória. A autora menciona ainda que esses profissionais não realizam essa atividade devido à falta de disponibilidade de tempo, número reduzido de enfermeiros na unidade de centro cirúrgico, responsabilidade por outros setores, pacientes que internavam no dia da cirurgia. 
Silva ${ }^{(28)}$, afirma que no Brasil, infelizmente são poucas as instituições que valorizam a sistematização da assistência, e que a ordenação e direcionamento das atividades não beneficiarão somente os enfermeiros, mas também, as próprias instituições que encontrarão, na sistematização, uma ferramenta para avaliar o trabalho desenvolvido.

Leite $^{(29)}$ ao analisar a percepção do enfermeiro, no período perioperatório, em relação à assistência de enfermagem prestada ao paciente cirúrgico idoso e à percepção desse paciente, no período perioperatório, em relação à assistência de enfermagem, comparando-as entre si, fez algumas sugestões diante dos resultados obtidos. Sugeriu aos enfermeiros do centro cirúrgico, que se preocupem em desenvolver a assistência sistematizada de enfermagem ao paciente idoso, no período perioperatório, a qual reverterá em benefício para o paciente, individualizando-o e promovendo atendimento de suas necessidades básicas e, ao enfermeiro, conferirá o conhecimento sobre o paciente, possibilitando um planejamento qualificado da assistência a ser prestada. Sugeriu também, para a instituição estudada, que o SAEP seja viabilizado, ainda que não sejam seguidos todos os seus passos e etapas, mas que padrões mínimos sejam estabelecidos. Essas sugestões ressaltam a importância do intercâmbio entre os enfermeiros das unidades de internação e centro cirúrgico, do registro de dados pertinentes sobre os pacientes, das ações de enfermagem diferenciadas para o paciente idoso, da admissão do paciente pelo enfermeiro do centro cirúrgico, e da visita pré e pós-operatória realizada pelo enfermeiro do centro cirúrgico.

Para Dalri ${ }^{(30)}$, o profissional de enfermagem, ao utilizar a assistência de enfermagem de forma sistematizada, sustentado por referencial teórico de 
enfermagem, estará habilitado a fomentar conhecimentos teórico e prático, alicerçando relações de trabalho concretas.

Assim, segundo a autora, o enfermeiro precisa estabelecer conhecimento com as fases do processo de enfermagem, refletir e adaptar à sua realidade e clientela e, também, incorporar os conceitos propostos pelo modelo, a fim de alcançar o objetivo idealizado.

No âmbito hospitalar, conforme Dalri ${ }^{(30)}$, quando o enfermeiro delimita seu exercício profissional na assistência, à luz de um modelo conceitual, posiciona-se como uma pessoa essencial para promover o cuidado e o restabelecimento do paciente. A atitude desse enfermeiro na sua avaliação clínica, na orientação e condução de sua equipe e suas ações administrativas, assistenciais, educativas e de pesquisa são asseguradas e fundamentadas, tendo autonomia em suas ações.

Frente ao exposto, o SAE, aliado a um marco conceitual no período perioperatório (SAEP), proporcionará uma assistência integral e individualizada, com a participação da família e daqueles que são importantes ao paciente; possibilitará também a identificação dos diagnósticos e, como conseqüência, a implementação do plano de cuidados durante a cirurgia e continuação da assistência iniciada no pré-operatório. Acreditamos ainda, na importância da sistematização como uma forma de integração da equipe multidisciplinar junto ao paciente e família e, principalmente, se conseguirmos fazer com que o paciente sinta-se confortado, suas ansiedades diminuídas e, sentindo-se como parte integrante e participativa de um processo, grande parte de nossos objetivos terão sido alcançados e sua importância justificada. 
Entendemos que uma das formas para se estabelecer não um protocolo ou uma norma, mas uma forma de atendimento integral e individualizado ao paciente seja o SAEP, considerando a comunicação, essencial para esta atividade.

\subsection{Assistência de enfermagem no período de recuperação pós- anestésica}

A intervenção cirúrgica constitui para o paciente um acontecimento que envolve risco de morte, devido à agressão anestésico-cirúrgica. As primeiras 24 horas do pós-operatório exigem uma atenção especial da equipe de saúde, pois o paciente pode apresentar distúrbios pulmonares, cardiovasculares, renais, entre outros, que devem ser reconhecidos e tratados imediatamente ${ }^{(4)}$. A fim de prevenir estas intercorrências e atendê-las prontamente, é necessário que o paciente permaneça em uma unidade específica, isto é, na sala de recuperação pós-anestésica, até que haja a recuperação da consciência, a normalização dos reflexos e dos sinais vitais, sob observação e cuidados constantes da equipe de enfermagem ${ }^{(31)}$.

Deve-se considerar, na projeção de uma unidade de recuperação pósanestésica, a máxima segurança, contribuindo para o conforto do paciente e, principalmente, permitindo tanto a observação e prevenção de complicações como ações de emergência eficazes no controle de intercorrências. Esta unidade deve ser auto-suficiente, ter espaço satisfatório e equipamentos necessários para uso em situações de rotina e emergência. Para tanto, deve-se contar com uma equipe treinada e apta para atender o paciente não só em situações de rotina, como também nas emergências do pós-operatório ${ }^{(32,33,34)}$.

As equipes de enfermagem e anestesiologista, da recuperação pósanestésica, têm desenvolvido um trabalho conjunto, com a finalidade de oferecer 
assistência integral e segura ao paciente cirúrgico, subsidiado pelo domínio crescente do conhecimento científico e pela prática específica desta área ${ }^{(4)}$.

Segundo Silva, Rodrigues e Cezareti ${ }^{(35)}$, nesta unidade, onde o tempo médio de permanência do paciente é de 1 a 6 horas, a assistência prestada pela equipe de saúde tem como finalidade:

- Oferecer suporte ao paciente no período de recuperação da anestesia, até que os reflexos protetores estejam presentes, os sinais vitais voltem à normalidade e seja recuperada a consciência;

- Prevenir ou tratar possíveis complicações resultantes do ato anestésico ou cirúrgico;

- Estabelecer medidas para aliviar a dor pós-operatória;

- Proporcionar ao paciente atendimento seguro, em se tratando de um local provido de recursos materiais específicos e humanos, preparados para a prestação da assistência neste período.

A assistência de enfermagem deve ser centrada na pessoa do paciente, um indivíduo considerado dependente da enfermagem devido ao seu estado de inconsciência ou de semi consciência, merecedor de um atendimento adequado em suas necessidades básicas afetadas, na prevenção de complicações que, porventura, possam ocorrer. Mesmo que em algumas instituições se estabeleçam rotinas, a individualização do paciente é necessário, evitando o tratamento de um "caso

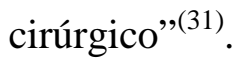

Para prestar cuidado de enfermagem no período pós-operatório, mais especificamente no período de recuperação pós-anestésica, é necessário que a enfermeira receba informações sobre o período transoperatório, quanto a: 
- condição geral do paciente (tanto físico como mental e emocional, incluindo-se aqui o nível de ansiedade em que o paciente foi admitido na sala de operação);

- tipo de cirurgia realizada;

- tipo de anestesia realizada;

- problema ou complicação ocorrida nesse período;

- posição do paciente durante o ato cirúrgico;

- local da placa de dispersão;

- local de curativos, sondas, drenos;

- medicações recebidas;

- perdas.

Além disso, há necessidade de informações da unidade de origem tais como transtornos ortopédicos, problemas nos órgãos dos sentidos e problemas físicos não diretamente relacionados ao problema cirúrgico ${ }^{(36)}$.

$\mathrm{Na}$ admissão em sala de recuperação pós-anestésica, a enfermeira deve, após colocar o paciente em posição adequada, observar e anotar os seguintes aspectos:

1. permeabilidade de vias aéreas e saturação de oxigênio;

2. nível de consciência: responde a estímulos tácteis ou dolorosos? Responde a comandos verbais simples? Há movimentos voluntários?

3. sinais vitais, comparando-os aos dados do pré-operatório;

4. coloração da pele: presença ou não de cianose de extremidade e perilabial;

5. condições do curativo: presença ou não de sangramento, de secreção; 
6. presença de tubulações ou drenagens: devem permanecer abertos ou fechados? Com aspiração contínua ou não?

7. presença de infusão endovenosa: local de inserção do cateter; verificação do tipo e quantidade de solução que está sendo administrada.

Os cuidados de enfermagem ao paciente, neste período, devem ser prestados objetivando a segurança, o conforto e o bem estar do paciente. Sendo assim, a avaliação da função cardiovascular e perfusão tissular, função respiratória, sangramentos, conforto, higiene e alívio da dor se faz necessário ${ }^{(35)}$.

Segundo Peniche ${ }^{(37)}$, não é só na área da assistência de enfermagem que se pode ter uma perspectiva de melhorar o cuidado prestado, outras áreas de atuação da enfermeira de recuperação pós-anestésica podem indiretamente beneficiar o cuidado, como a área da pesquisa, educação e administrativa.

\subsection{Comunicação e continuidade do cuidado}

A assistência ao paciente cirúrgico não deve ser limitada ao período de recuperação pós-anestésica.. As primeiras 24 horas do pós-operatório devem ser consideradas como uma fase crítica. Após receber alta deste setor, a assistência continua nas unidades de origem. Dessa forma, observamos que o enfermeiro da unidade de recuperação pós-anestésica deve oferecer, além da segurança e tratamento às necessidades afetadas do paciente cirúrgico, a garantia de continuidade desta assistência prestada, oferecendo subsídios para o planejamento dos cuidados nas unidades de pós-operatório ${ }^{(4)}$.

Para a continuidade da assistência prestada, é necessário ter o conhecimento do relatório do período transoperatório, com anotações e informações 
completas, além dos cuidados de enfermagem prestados no período pós-anestésico (28)

Segundo Anderson e Helms ${ }^{(38)}$, a continuidade do cuidado é o princípio da prática profissional da enfermagem, sendo que a comunicação sobre as condições e necessidades do paciente, entre os profissionais da saúde, é fundamental para se alcançar essa meta.

Esses mesmos autores fazem uma revisão de literatura, descrevendo as variáveis que podem afetar a comunicação, entre elas: volume versus tipo de informações versus qualidade das informações; estrutura das informações (formal/informal); características organizacionais e características do cliente. Eles concluem que o conhecimento, sobre as dinâmicas de comunicação, constitui a principal estratégia para a promoção da continuidade do cuidado.

Desta forma, verificamos que a enfermagem assume um papel fundamental nos processos de comunicação pela geração de registro e pelo processamento de dados que contribuirão para um sistema de informação em saúde.

Para Schaefer citado por Fávero et al. ${ }^{(39)}$, a comunicação é um dos processos essenciais da atividade administrativa, e permite a realização de todos os demais processos; sem ela não existe uma ação coordenada, o que constitui a base da administração. A comunicação é um ato essencial à existência humana. Comunicarse, verdadeiramente, implica em uma série de aspectos que, se não estiverem claros para as pessoas envolvidas, podem gerar falta de entendimento, levando, muitas vezes, ao fracasso da relação entre eles ${ }^{(40)}$.

Sendo o registro de enfermagem um meio de comunicação, Welter e Reiff ${ }^{(41)}$ salientam que o mesmo, quando adequado e conciso, contribui para a 
continuidade do cuidado prestado, além de possibilitar um atendimento mais rápido durante uma emergência.

Para Hall e Doran $^{(42)}$, a percepção dos enfermeiros em relação à qualidade da assistência prestada está associada aos modelos de registro de enfermagem e a criação dos mesmos permitem melhor comunicação entre as unidades e melhor coordenação do cuidado, representando um desafio aos profissionais.

Segundo Patterson et $\mathrm{al}^{(43)}$, as clínicas e os gerentes de enfermagem buscam clareza e compreensão dos dados clínicos do paciente, procurando utilizar o menor tempo possível na documentação, devido, principalmente, ao grande volume de transferências de pacientes. Assim, através do desenvolvimento do sistema informatizado, tornou-se viável obter os dados clínicos, fundamentais para melhor avaliação do paciente, por um acesso mais rápido. Conclui-se que esses sistemas de comunicação podem ser padronizados e validados intra e interorganizações, diminuindo o tempo de coleta dos dados e a redundância de intervenções, garantindo a satisfação do cliente, a redução de custos e a continuidade do cuidado.

Outro sistema de comunicação, encontrado na literatura e que, se utilizado de maneira eficiente, permite a continuidade da assistência de enfermagem é a passagem de plantão por telefone ou pessoalmente.

Segundo Potter e Perry ${ }^{(44)}$, quando o cliente está pronto para a alta da recuperação pós-anestésica, o enfermeiro deve telefonar para unidade de clínica cirúrgica para relatar seus dados clínicos, visto que a passagem de plantão auxilia o enfermeiro dessa unidade a antecipar as necessidades especiais do cliente e a obter os equipamentos necessários. 
Lamond $^{(45)}$, ao realizar um estudo para examinar o objetivo da passagem de plantão como meio de comunicação, concluiu que a passagem de plantão auxilia o planejamento do cuidado com maior eficácia.

Assim, utilizando esses recursos de comunicação, a enfermagem torna-se o elo integrador do sistema de informação em saúde, concentrando as informações a respeito do quadro do paciente e das ações que estão sendo implementadas pelas várias equipes de saúde, sendo a passagem de plantão, o momento que permite a integração destes dados e o planejamento de medidas futuras.

Diante do exposto, vimos que vários sistemas de comunicação auxiliam a continuidade do cuidado ao paciente cirúrgico, porém cabe ressaltar quais informações são necessárias para que a mesma seja alcançada, uma vez que as primeiras 24 horas do período pós-operatório requerem uma atenção especial da equipe de saúde.

Segundo Potter e Perry ${ }^{(44)}$, o enfermeiro avalia a alta da recuperação pósanestésica com base na estabilidade dos sinais vitais em comparação com os dados pré-operatórios. Outros critérios para a alta incluem orientação quanto ao ambiente, ausência de complicações, drenagem controlada da ferida, débito urinário adequado e equilíbrio hidroeletrolítico.

Essa mesma autora informa que os dados clínicos devem ser transmitidos às enfermeiras das clínicas cirúrgicas e incluem: sinais vitais, o tipo de cirurgia e anestesia utilizada, a perda sangüínea, o nível de consciência, a condição física geral e a presença de linhas parenterais ou sonda de drenagem.

Muitas equipes da recuperação pós-anestésica utilizam um sistema objetivo de pontuação que ajuda a delinear quando os clientes devem receber alta 
denominado de índice de avaliação de Aldrete e $\operatorname{Kroulik}^{(49)}$. Este tem sido adotado em diversos serviços, estabelecendo uma linguagem comum entre os médicos e enfermeiros que avaliam o paciente, baseado em cinco parâmetros: respiração, consciência, circulação, atividade muscular e saturação de oxigênio ${ }^{(35)}$.

Além de permitir uma linguagem comum entre a equipe, o uso de um instrumento de registro em recuperação pós-anestésica, permite avaliar a alta do paciente cirúrgico de forma sistematizada e assim reduzir o número de intercorrências pós-alta.

Como preconiza Posso ${ }^{(46)}$, um instrumento para o controle das condições dos pacientes nas salas de recuperação pós-anestésica, possibilita determinar o tempo de permanência dos pacientes para que não seja exageradamente curto ou longo, além da observação sistemática de sinais vitais, curativo, mobilidade, nível de consciência, comportamento, coloração de mucosas e extremidades. Ou seja, constitui-se uma "avaliação racionalizada das condições físicas dos pacientes na sala de recuperação pós-anestésica, podendo ser adotado de forma sistematizada”. 


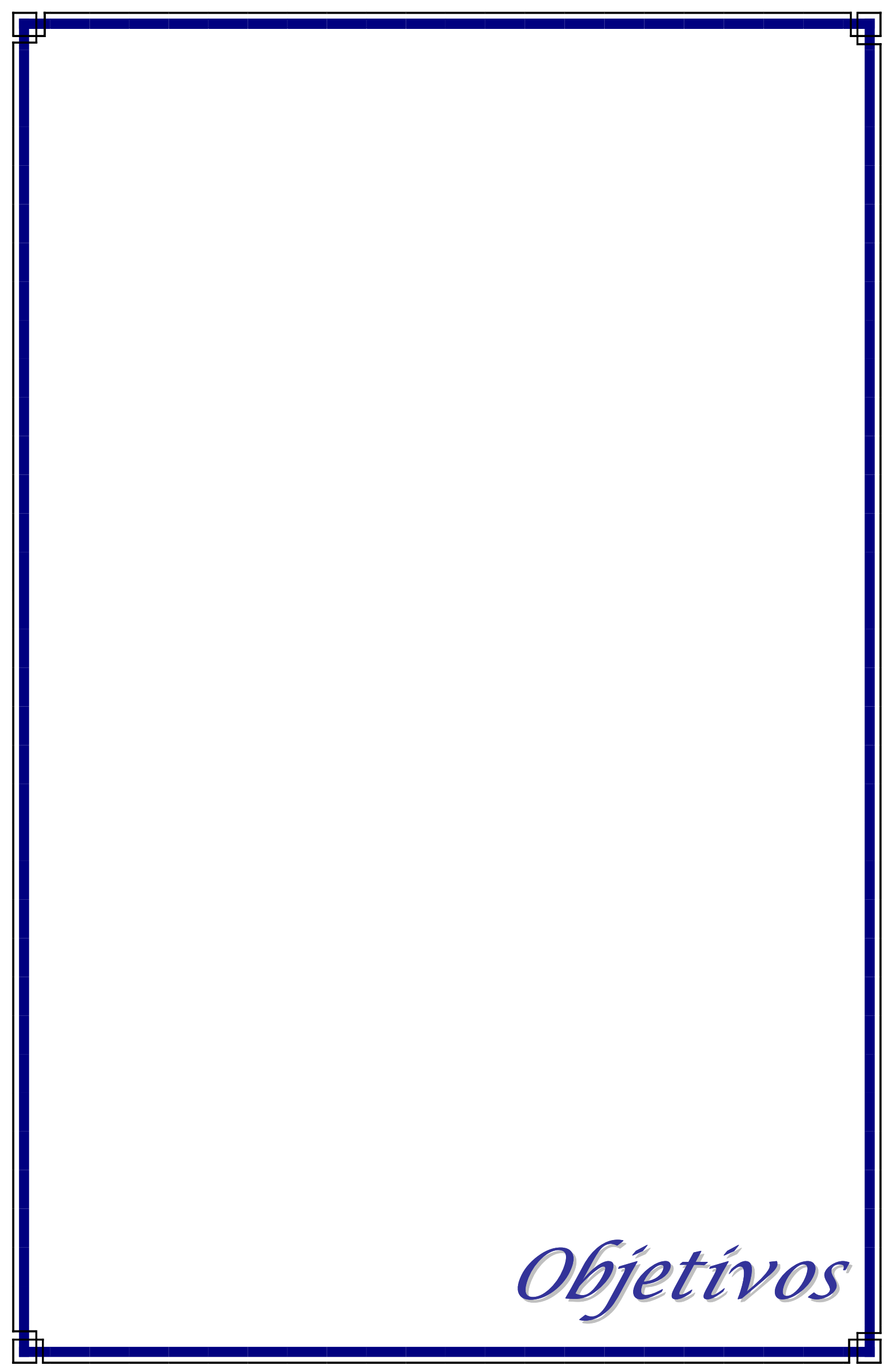




\section{OBJETIVOS}

\subsection{Objetivo geral}

Conhecer a avaliação feita, pelos enfermeiros das unidades pósoperatórias, a respeito da continuidade da assistência de enfermagem ao paciente cirúrgico.

\subsection{Objetivos específicos}

$\checkmark$ Identificar as dificuldades apresentadas pelos enfermeiros na obtenção dos dados clínicos referentes ao período de recuperação pós-anestésica.

Identificar a melhor estratégia para obter os dados clínicos necessários para a continuidade da assistência de enfermagem ao paciente cirúrgico, após receber alta da sala de recuperação pós-anestésica.

$\checkmark$ Identificar os dados clínicos, referentes ao período de recuperação pósanestésica, considerados necessários para o planejamento da assistência de enfermagem no período pós-operatório. 


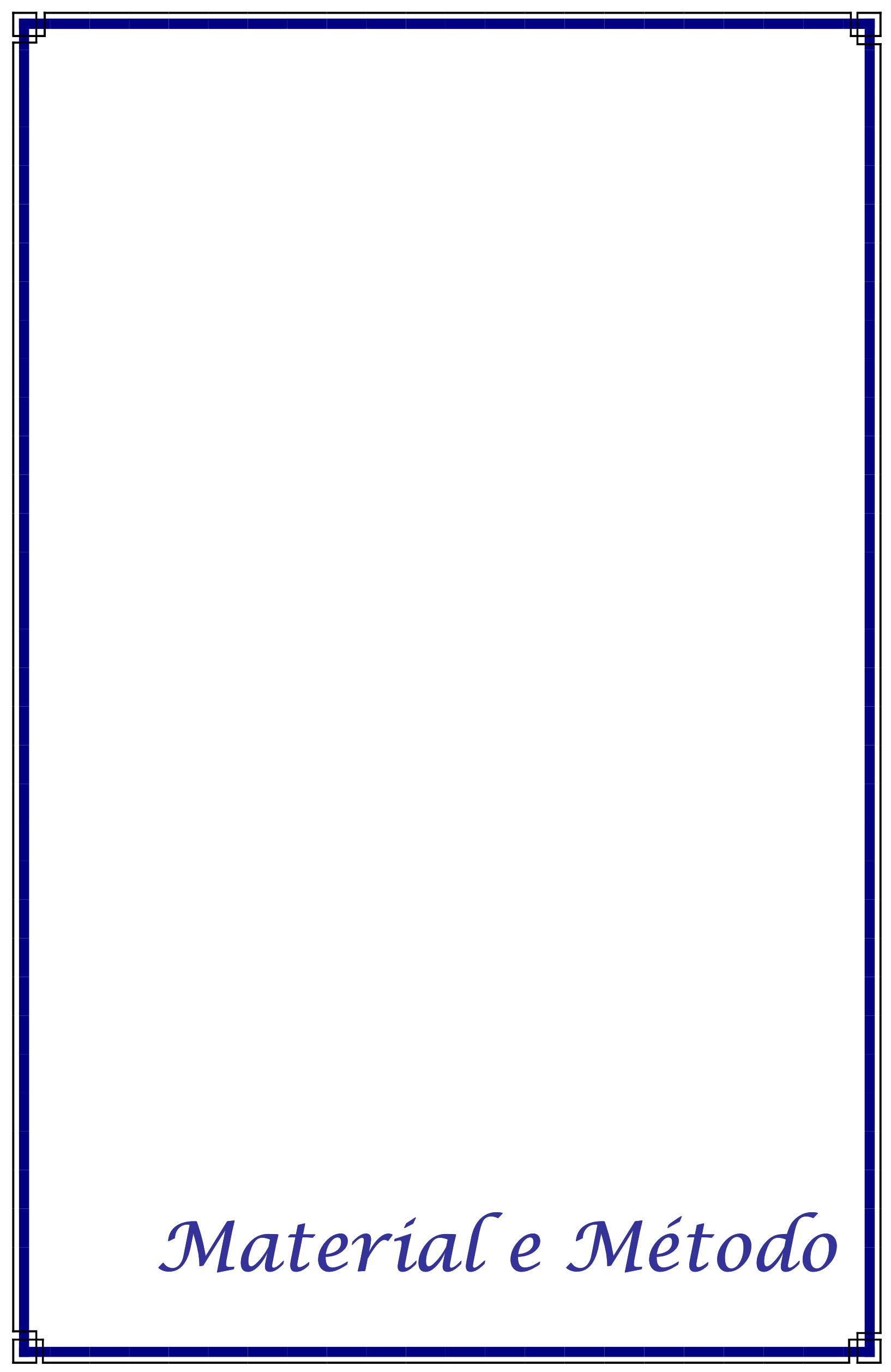




\section{MATERIAL E MÉTODO}

\subsection{Tipo de Estudo}

Trata-se de um estudo descritivo, exploratório, de campo, com abordagem quantitativa.

\subsection{Campo de estudo}

Esta pesquisa foi desenvolvida em duas instituições hospitalares identificadas como I e II, sendo que na instituição I, o SAE, estava em processo de implantação e, na II, o mesmo já se encontrava implantado:

- Instituição Hospitalar I: foram incluídas todas as unidades (Particular/Convênio/Sistema Único de Saúde - SUS), infantil e adulto, destinadas a admitir pacientes provenientes da sala de recuperação pós-anestésica, de um Hospital Universitário, localizado na cidade de Bragança Paulista.

- Instituição Hospitalar II: foram incluídas todas as unidades do SUS, infantil e adulto, destinadas a admitir pacientes provenientes da sala de recuperação pós-anestésica, de um Hospital Estadual, localizado na cidade de Sumaré.

\subsection{População do estudo}

A população do estudo foi constituída por enfermeiros das instituições hospitalares I e II, dos períodos, da manhã, da tarde e da noite, com experiência em assistir pacientes cirúrgicos provenientes da sala de recuperação pós-anestésica.

\subsection{Fonte dos dados}


Para a coleta de dados foi utilizado um formulário (Anexo A), composto por questões abertas e fechadas, dividido em duas partes:

A Parte I compreende os dados sócio-demográficos como:

- setor de trabalho ou cargo ocupado;

- tempo de trabalho no setor ou no cargo ocupado;

- jornada de trabalho;

- tempo de formação;

- cursos de especialização realizados ou outros.

A Parte II compõe-se de quatro questões:

- Questões 1 e 2 respectivamente, questiona as dificuldades, mais freqüentes, que interferem na obtenção dos dados clínicos necessários para o período pós-operatório imediato e qual a melhor estratégia para receber as informações pertinentes a este período.

- Questão 3 questiona a avaliação feita pelos enfermeiros sobre o instrumento de registro da recuperação pós-anestésica por ser um meio legal e concreto de comunicação.

- Questão 4 identifica se os dados clínicos contidos no instrumento de registro são consultados; se sim, qual a importância dos mesmos, se não, qual o motivo.

\subsection{Procedimentos:}

\subsubsection{Procedimento ético-legal}


- O projeto de pesquisa foi submetido à apreciação do Comitê de Ética em Pesquisa das Instituições em estudo.

- Somente participaram deste estudo os profissionais que estiveram de acordo com o Termo de Consentimento (Anexo B) e participaram espontaneamente da pesquisa.

\subsubsection{Procedimento de coleta de dados}

Após a aprovação e a autorização do Comitê de Ética em Pesquisa das duas instituições (Anexos C e D), os dados foram coletados no período de julho e agosto de 2005. Foi realizada uma visita nos setores acima especificados, com a finalidade de apresentar à amostra estudada, os objetivos da pesquisa e o Termo de Consentimento (Anexo B). Após autorização dos mesmos, foi aplicado, pela pesquisadora, uma entrevista direcionada pelo instrumento de coleta de dados, previamente elaborado (Anexo A). Para àqueles que, por algum motivo, não puderam participar deste momento, foi agendada uma nova data, atendendo a disponibilidade do profissional durante sua jornada de trabalho.

\subsubsection{Procedimento de análise dos dados}

Os dados foram analisados segundo as freqüências relativa e absoluta, agrupados e discutidos em forma de tabelas e quadros. 


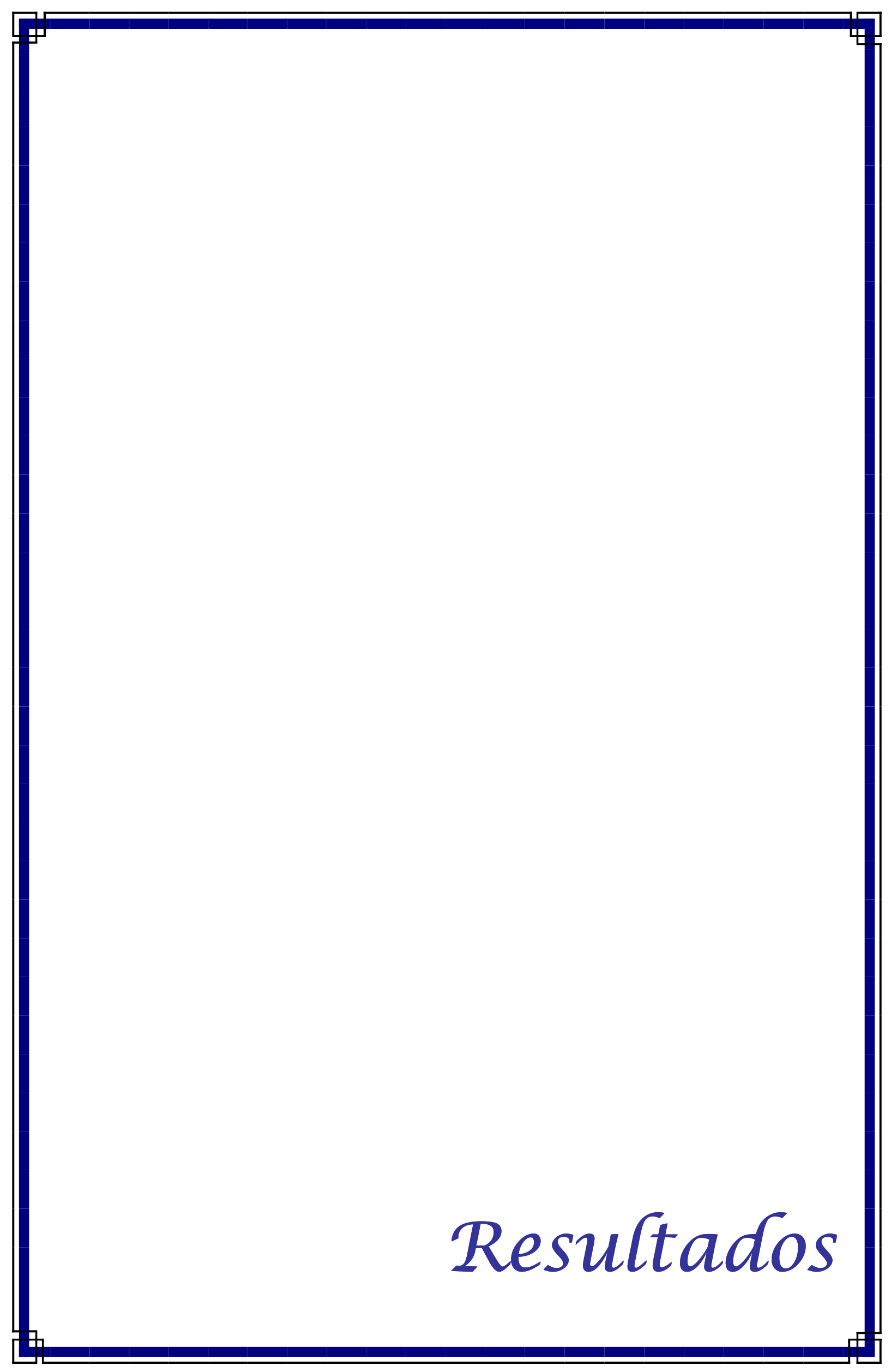




\section{RESULTADOS}

Os resultados são apresentados em duas etapas. A primeira consiste na caracterização da amostra e a segunda responde aos objetivos do estudo.

Tabela 1 - Caracterização da amostra estudada segundo setores / cargos envolvidos, tempo de trabalho, jornada de trabalho, tempo de formação e cursos de especialização ou outros. São Paulo - 2005.

\begin{tabular}{|c|c|c|c|c|c|c|}
\hline \multirow[t]{2}{*}{ Características } & \multicolumn{2}{|c|}{ Hospital I } & \multicolumn{2}{|c|}{ Hospital II } & \multicolumn{2}{|c|}{ Total } \\
\hline & $\mathbf{n}$ & $\%$ & $\mathbf{n}$ & $\%$ & $\mathbf{n}$ & $\%$ \\
\hline \multicolumn{7}{|l|}{ Setores / Cargos } \\
\hline Clínica Médica & 2 & 7,69 & 6 & 18,18 & 8 & 13,56 \\
\hline Clínica Cirúrgica & 1 & 3,85 & 4 & 12,12 & 5 & 8,47 \\
\hline Clínica Mista / Especialidades & 1 & 3,85 & 4 & 12,12 & 5 & 8,47 \\
\hline Ginecologia & 2 & 7,69 & 4 & 12,12 & 6 & 10,17 \\
\hline Apartamento / Convênio & 2 & 7,69 & 0 & 0,00 & 2 & 3,39 \\
\hline Oncologia & 1 & 3,85 & 0 & 0,00 & 1 & 1,69 \\
\hline Nefrologia / Hemodiálise & 3 & 11,54 & 0 & 0,00 & 3 & 5,08 \\
\hline Pediatria & 2 & 7,69 & 1 & 3,03 & 3 & 5,08 \\
\hline UTI Neonatal / Infantil & 4 & 15,38 & 7 & 21,21 & 11 & 18,64 \\
\hline UTI Adulto & 3 & 11,54 & 7 & 21,21 & 10 & 16,95 \\
\hline Pronto Socorro & 1 & 3,85 & 0 & 0,00 & 1 & 1,69 \\
\hline Supervisão & 4 & 15,38 & 0 & 0,00 & 4 & 6,78 \\
\hline \multicolumn{7}{|l|}{ Tempo de trabalho } \\
\hline $0-5$ anos & 24 & 92,31 & 32 & 96,97 & 56 & 94,92 \\
\hline $6-10$ anos & 1 & 3,85 & 1 & 3,03 & 2 & 3,39 \\
\hline $11-15$ anos & 1 & 3,85 & 0 & 0,00 & 1 & 1,69 \\
\hline Acima de 15 anos & 0 & 0,00 & 0 & 0,00 & 0 & 0,00 \\
\hline \multicolumn{7}{|l|}{ Jornada de trabalho } \\
\hline 6 horas/dia & 18 & 69,23 & 19 & 57,58 & 37 & 62,71 \\
\hline 8 horas/dia & 2 & 7,69 & 0 & 0,00 & 2 & 3,39 \\
\hline $12 \times 36$ & 6 & 23,08 & 14 & 42,42 & 20 & 33,90 \\
\hline \multicolumn{7}{|l|}{ Tempo de formação } \\
\hline $0-5$ anos & 20 & 76,92 & 18 & 54,55 & 38 & 64,41 \\
\hline $6-10$ anos & 3 & 11,54 & 9 & 27,27 & 12 & 20,34 \\
\hline $11-15$ anos & 2 & 7,69 & 2 & 6,06 & 4 & 6,78 \\
\hline Acima de 15 anos & 1 & 3,85 & 4 & 12,12 & 5 & 8,47 \\
\hline \multicolumn{7}{|l|}{ Cursos } \\
\hline Enfermagem Médico-Cirúrgica & 0 & 0,00 & 2 & 6,06 & 2 & 3,39 \\
\hline Enfermagem Cirúrgica & 0 & 0,00 & 0 & 0,00 & 0 & 0,00 \\
\hline Enfermagem em Centro Cirúrgico & 0 & 0,00 & 0 & 0,00 & 0 & 0,00 \\
\hline Enfermagem em UTI & 4 & 15,38 & 6 & 18,18 & 10 & 16,95 \\
\hline Enfermagem em Pronto Socorro & 0 & 0,00 & 0 & 0,00 & 0 & 0,00 \\
\hline Enfermagem Oncológica & 0 & 0,00 & 0 & 0,00 & 0 & 0,00 \\
\hline Enfermagem em Urologia / Nefrologia & 2 & 7,69 & 0 & 0,00 & 2 & 3,39 \\
\hline Enfermagem em Ginecologia / Obstetrícia & 1 & 3,85 & 0 & 0,00 & 1 & 1,69 \\
\hline Administração em Enfermagem & 3 & 11,54 & 1 & 3,03 & 4 & 6,78 \\
\hline Mestrado & 0 & 0,00 & 2 & 6,06 & 2 & 3,39 \\
\hline Doutorado & 0 & 0,00 & 0 & 0,00 & 0 & 0,00 \\
\hline Outros* & 4 & 15,38 & 7 & 21,21 & 11 & 18,64 \\
\hline Nenhum & 12 & 46,15 & 15 & 45,45 & 27 & 45,76 \\
\hline
\end{tabular}

* Estão incluídos os profissionais que fizeram mais de um curso acima especificado e/ou outros cursos, destacandose no Hospital I saúde pública e programa saúde da família (PSF) e no Hospital II saúde pública, PSF, pedagogia e atendimento pré-hospitalar. 
Conforme o critério de inclusão para a participação desta pesquisa, a amostra estudada foi constituída por enfermeiros com experiência na admissão de pacientes cirúrgicos provenientes da sala de recuperação pós-anestésica, totalizando 59 (100\%) enfermeiros, sendo $26(44,07 \%)$ do Hospital I e 33 (55,93\%) do Hospital II. Como mostram os dados da Tabela 1, no Hospital I, houve predomínio de enfermeiros da UTI neonatal/infantil $4(15,38 \%)$ e enfermeiros supervisores 4 $(15,38 \%)$. Fizeram também parte da amostra enfermeiros dos setores de oncologia, hemodiálise e pronto socorro, uma vez que tinham experiência em assistir pacientes cirúrgicos. No Hospital II houve predomínio de enfermeiros da UTI neonatal 7 $(21,21 \%)$ e da UTI adulto 7 (21,21\%). A maioria declarou possuir um tempo de trabalho, no setor, entre 0 e 5 anos, sendo 24 (92,31\%) do Hospital I e 32 (96,97\%) do Hospital II. A jornada de trabalho predominante foi no período de 6 horas, sendo $18(69,23 \%)$ do Hospital I e 19 (57,58\%) do Hospital II e, em seguida, 12 X36 horas, sendo $6(23,08 \%)$ do Hospital I e $14(42,42 \%)$ do Hospital II, com exceção dos profissionais do Hospital I, que atuavam em oncologia e hemodiálise, onde a jornada de trabalho era de 8 horas. Houve predomínio de enfermeiros com formação entre 0 e 5 anos, sendo 20 (76,92\%) do Hospital I e 18 (54,55\%) do Hospital II e 32 (54,24\%) tinham cursos de pós-graduação, sendo 14 (43,75\%) do Hospital I e 18 (56,25\%) do Hospital II. Tanto no Hospital I quanto no Hospital II, destacaram-se os enfermeiros com especialização em UTI, sendo $4(15,38 \%)$ do Hospital I e $6(18,18 \%)$ do Hospital II e àqueles que fizeram mais de uma especialização, sendo $4(15,38 \%)$ do Hospital I e 7 (21,21\%) do Hospital II. 
Tabela 2 - Distribuição das dificuldades apresentadas pelos enfermeiros, na obtenção dos dados clínicos do paciente referente ao período de recuperação pós-anestésica. São Paulo - 2005.

\begin{tabular}{|c|c|c|c|c|c|c|c|c|c|c|c|c|c|c|c|c|}
\hline \multirow[t]{3}{*}{ Dificuldades } & & \multicolumn{7}{|c|}{ Hospital I } & \multicolumn{7}{|c|}{ Hospital II } & \multirow[t]{3}{*}{ Global } \\
\hline & & \multicolumn{4}{|c|}{ OCORRE } & \multirow[b]{2}{*}{ 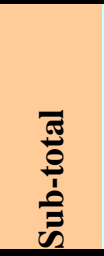 } & \multirow[b]{2}{*}{$\begin{array}{l}\text { Não } \\
\text { Ocorre }\end{array}$} & \multirow[b]{2}{*}{$\begin{array}{c}\text { Sem } \\
\text { Opinião }\end{array}$} & \multicolumn{4}{|c|}{ OCORRE } & \multirow[b]{2}{*}{ 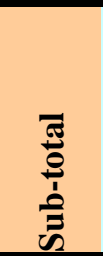 } & \multirow[b]{2}{*}{$\begin{array}{l}\text { Não } \\
\text { Ocorre }\end{array}$} & \multirow[b]{2}{*}{$\begin{array}{c}\text { Sem } \\
\text { Opinião }\end{array}$} & \\
\hline & & 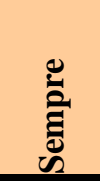 & 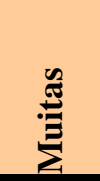 & $\underset{2}{\stackrel{2}{E}}$ & 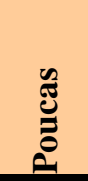 & & & & हैं & $\stackrel{\mathscr{\Xi}}{\stackrel{\mathscr{\Xi}}{\Xi}}$ & 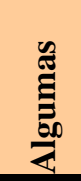 & $\begin{array}{l}\tilde{J} \\
0 \\
0\end{array}$ & & & & \\
\hline \multirow{2}{*}{ Ausência do instrumento } & $\mathrm{n}^{\circ}$ & 11 & 5 & 4 & 2 & 22 & 0 & 4 & 4 & 8 & 0 & 6 & 18 & 11 & 4 & 59 \\
\hline & $\%$ & 42,31 & 19,23 & 15,38 & 7,69 & 84,62 & 0,00 & 15,38 & 12,12 & 24,24 & 0,00 & 18,18 & 54,55 & 33,33 & 12,12 & 100 \\
\hline \multirow{2}{*}{$\begin{array}{l}\text { Inst. preenchido } \\
\text { incompleto }\end{array}$} & $\mathrm{n}^{\circ}$ & 2 & 4 & 6 & 0 & 12 & 0 & 14 & 7 & 11 & 0 & 7 & 25 & 2 & 6 & 59 \\
\hline & $\%$ & 7,69 & 15,38 & 23,08 & 0,00 & 46,15 & 0,00 & 53,85 & 21,21 & 33,33 & 0,00 & 21,21 & 75,76 & 6,06 & 18,18 & 100 \\
\hline \multirow{2}{*}{$\begin{array}{c}\text { Inst. sem as informações } \\
\text { necessárias }\end{array}$} & $\mathrm{n}^{\circ}$ & 14 & 1 & 3 & 1 & 19 & 3 & 4 & 2 & 13 & 0 & 4 & 19 & 4 & 10 & 59 \\
\hline & $\%$ & 53,85 & 3,85 & 11,54 & 3,85 & 73,08 & 11,54 & 15,38 & 6,06 & 39,39 & 0,00 & 12,12 & 57,58 & 12,12 & 30,30 & 100 \\
\hline \multirow{2}{*}{$\begin{array}{c}\text { Sem passagem de plantão } \\
\text { por telefone }\end{array}$} & $\mathrm{n}^{\circ}$ & 19 & 2 & 1 & 0 & 22 & 1 & 3 & 12 & 3 & 0 & 3 & 18 & 14 & 1 & 59 \\
\hline & $\%$ & 73,08 & 7,69 & 3,85 & 0,00 & 84,62 & 3,85 & 11,54 & 36,36 & 9,09 & 0,00 & 9,09 & 54,55 & 42,42 & 3,03 & 100 \\
\hline \multirow{2}{*}{$\begin{array}{l}\text { Plantão por telefone, } \\
\text { porém incompleto }\end{array}$} & $\mathrm{n}^{\circ}$ & 2 & 0 & 0 & 0 & 2 & 2 & 22 & 10 & 3 & 0 & 5 & 18 & 14 & 1 & 59 \\
\hline & $\%$ & 7,69 & 0,00 & 0,00 & 0,00 & 7,69 & 7,69 & 84,62 & 30,30 & 9,09 & 0,00 & 15,15 & 54,55 & 42,42 & 3,03 & 100 \\
\hline
\end{tabular}

Ainda foram citadas outras dificuldades:

Hospital I: falta de comunicação (5); falta de registro (2); falta de enfermeiros (1); falta de funcionários em geral (1).

Hospital II: falta de enfermeiros (1); falta de conhecimento da situação dos setores (1). 
Em relação às dificuldades apresentadas, pelos enfermeiros, para a obtenção dos dados clínicos do paciente, referente ao período de recuperação pósanestésica (Tabela 2), observou-se, no Hospital I, que as dificuldades citadas a seguir tiveram a mesma freqüência, com 22 relatos cada (84,62\%): ausência, no prontuário, do instrumento utilizado na recuperação pós-anestésica e ausência da passagem de plantão por telefone, seguidas da ausência de informações necessárias no instrumento $19(73,08 \%)$; preenchimento incompleto do instrumento $12(46,15 \%)$ e passagem incompleta de plantão por telefone $2(7,69 \%)$. Com relação ao nível de intensidade com que ocorreram estas dificuldades, a ausência da passagem de plantão por telefone foi a que apresentou um maior nível de intensidade (sempre), 19 (73,08\%), seguidas da ausência de informações necessárias no prontuário $14(53,85 \%)$ e ausência do instrumento no prontuário 11 (42,31\%). Além destas dificuldades, outras foram pontuadas como a falta de comunicação, de registro e de funcionários em geral por 9 enfermeiros $(34,62 \%)$. No Hospital II, as dificuldades mais frequientes, foram: preenchimento incompleto do instrumento 25 (75,76\%), seguidas da ausência de informações necessárias no instrumento 19 (57,58\%). E, ainda, com 18 relatos cada (54,55\%): ausência, no prontuário, do instrumento utilizado na recuperação pósanestésica, ausência da passagem de plantão por telefone e passagem incompleta de plantão por telefone. Como no Hospital I, a ausência da passagem de plantão por telefone foi a dificuldade de maior intensidade, $12(36,36 \%)$, verifica-se ainda que a ausência de informações necessárias no instrumento e preenchimento incompleto do instrumento também apresentaram um nível de intensidade importante (muitas vezes) $13(39,39 \%)$ e $11(33,33 \%)$, respectivamente. Ressalta-se que 2 enfermeiros $(6,06 \%)$ 
Elaine Reda

citaram, além das dificuldades pontuadas, outras como a falta de enfermeiros e de conhecimento da situação dos setores. 
Tabela 3 - Distribuição das estratégias utilizadas pelos enfermeiros para se obter informações do paciente com alta da recuperação pós-anestésica. São Paulo - 2005.

\begin{tabular}{lcccccc}
\hline Estratégias para se obter informações & \multicolumn{2}{c}{ Hospital I } & \multicolumn{2}{c}{ Hospital II } & \multicolumn{2}{c}{ Global } \\
\cline { 2 - 7 } & $\mathrm{n}$ & $\%$ & $\mathrm{n}$ & $\%$ & $\mathrm{n}$ & $\%$ \\
\hline Instrumento da RPA & 2 & 7,69 & 2 & 6,06 & 4 & 6,78 \\
Plantão por telefone & 0 & 0,00 & 1 & 3,03 & 1 & 1,69 \\
Plantão pelo funcionário do transporte & 2 & 7,69 & 0 & 0,00 & 2 & 3,39 \\
Sistema informatizado & 0 & 0,00 & 0 & 0,00 & 0 & 0,00 \\
Nenhuma informação é necessária & 0 & 0,00 & 0 & 0,00 & 0 & 0,00 \\
Instrumento RPA + Passagem por telefone & 17 & 65,38 & 10 & 30,30 & 27 & 45,76 \\
Outros* & 5 & 19,23 & 20 & 60,61 & 25 & 42,37 \\
\hline Total & 26 & 100 & 33 & 100 & 59 & 100 \\
\hline
\end{tabular}

* Hospital I: Instrumento da RPA + Sistema informatizado (2); Passagem pelo funcionário do transporte + Instrumento da RPA + Passagem por telefone (1); Passagem por telefone + Sis tema informatizado (2).

Hospital II: Instrumento da RPA + Passagem pelo funcionário do transporte (3); Instrumento da RPA e pessoalmente pelo enfermeiro do CC (1); Instrumento da RPA + Passagem pelo funcionário do transporte + Sistema informatizado (2); Instrumento da RPA + Sistema informatizado (3); Pas sagem por telefone + Sistema informatizado (2); Passagem pelo funcionário do transporte + Sistema informatizado + Instrumento da RPA + Passagem por telefone (2); Passagem pelo funcionário do transporte + Instrumento da RPA + Passagem por telefone (4); Passagem pelo funcionário do tranporte + Passagem por telefone somente dos pacientes que necessitem de maior observação (1); Sistema informatizado + Instrumento da RPA + Passagem por telefone (1); Passagem de enfermeiro para enfermeiro no leito (1). 
Quanto às estratégias para se obter informações do paciente que recebe alta da sala de recuperação pós-anestésica (Tabela 3), no Hospital I, 17 enfermeiros $(65,38 \%)$ responderam que utilizam o instrumento de registro da recuperação pósanestésica associado à passagem de plantão por telefone; $5(19,23 \%)$ relatam diversos meios de se obter informações; 2 (7,69\%) se utilizam do instrumento de registro da RPA e $2(7,69 \%)$ obtêm as informações por meio do funcionário que transporta o paciente da sala de recuperação pós-anestésica para a unidade de origem. No Hospital II, 20 enfermeiros $(60,61 \%)$ relatam diversos meios de se obter informações; $10(30,30 \%)$ se utilizam do instrumento de registro da RPA associado à passagem de plantão; $2(6,06 \%)$ se utilizam somente do instrumento da RPA e 1 $(3,03 \%)$ faz uso do telefone.

Apesar de mais de uma estratégia ser citada para a obtenção de informações referentes ao paciente com alta da recuperação pós-anestésica, foi questionado aos enfermeiros, a avaliação feita sobre o instrumento de registro utilizado por ser um meio concreto de comunicação (Tabela 4). 
Tabela 4 - Distribuição da avaliação, feita pelos enfermeiros, sobre o instrumento de registro utilizado na recuperação pós-anestésica. São Paulo 2005.

\begin{tabular}{|c|c|c|c|c|c|c|c|c|c|c|c|c|c|c|c|c|}
\hline \multirow[t]{3}{*}{ Afirmações } & & \multicolumn{7}{|c|}{ Hospital I } & \multicolumn{7}{|c|}{ Hospital II } & \multirow[t]{3}{*}{ Global } \\
\hline & & \multicolumn{3}{|c|}{ CONCORDA } & \multicolumn{3}{|c|}{ DISCORDA } & \multirow[b]{2}{*}{ 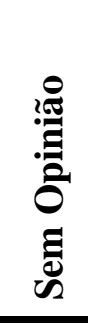 } & \multicolumn{3}{|c|}{ CONCORDA } & \multicolumn{3}{|c|}{ DISCORDA } & \multirow[b]{2}{*}{ 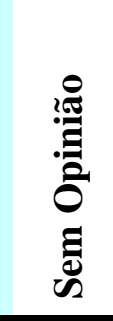 } & \\
\hline & & 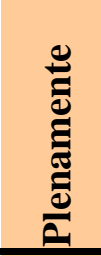 & 帝 & 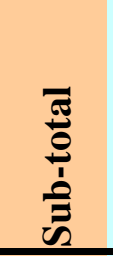 & 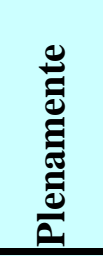 & 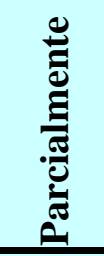 & 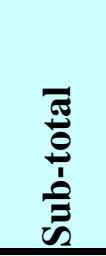 & & 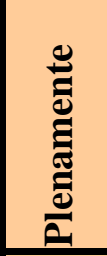 & 莺 & 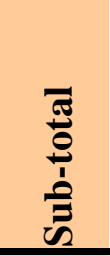 & 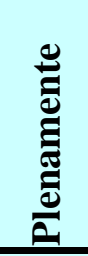 & 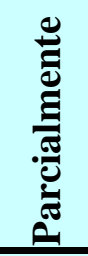 & 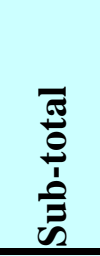 & & \\
\hline \multirow{2}{*}{ Auxilia no planejamento } & $\mathrm{n}^{\circ}$ & 13 & 11 & 24 & 1 & 1 & 2 & 0 & 22 & 7 & 29 & 0 & 1 & 1 & 3 & 59 \\
\hline & $\%$ & 50,00 & 42,31 & 92,31 & 3,85 & 3,85 & 7,69 & 0,00 & 66,67 & 21,21 & 87,88 & 0,00 & 3,03 & 3,85 & 11,54 & 100 \\
\hline \multirow{2}{*}{ Promove a continuidade } & $\mathrm{n}^{\circ}$ & 15 & 5 & 20 & 3 & 3 & 6 & 0 & 21 & 8 & 29 & 1 & 1 & 2 & 2 & 59 \\
\hline & $\%$ & 57,69 & 19,23 & 76,92 & 11,54 & 11,54 & 23,08 & 0,00 & 63,64 & 24,24 & 87,88 & 3,03 & 3,03 & 7,69 & 7,69 & 100 \\
\hline \multirow{2}{*}{ É um indicador de qualidade } & $\mathrm{n}^{\circ}$ & 8 & 7 & 15 & 4 & 7 & 11 & 0 & 24 & 1 & 25 & 1 & 3 & 4 & 4 & 59 \\
\hline & $\%$ & 30,77 & 26,92 & 57,69 & 15,38 & 26,92 & 42,31 & 0,00 & 72,73 & 3,03 & 75,76 & 3,03 & 9,09 & 15,38 & 15,38 & 100 \\
\hline \multirow{2}{*}{ É um meio de comunicação } & $\mathrm{n}^{\circ}$ & 9 & 7 & 16 & 4 & 5 & 9 & 1 & 18 & 8 & 26 & 2 & 3 & 5 & 2 & 59 \\
\hline & $\%$ & 34,62 & 26,92 & 61,54 & 15,38 & 19,23 & 34,62 & 3,85 & 54,55 & 24,24 & 78,79 & 6,06 & 9,09 & 19,23 & 7,69 & 100 \\
\hline \multirow{2}{*}{$\begin{array}{l}\text { É ummeio de documentar } \\
\text { o cuidado }\end{array}$} & $\mathrm{n}^{\circ}$ & 14 & 7 & 21 & 1 & 3 & 4 & 1 & 29 & 0 & 29 & 1 & 1 & 2 & 2 & 59 \\
\hline & $\%$ & 53,85 & 26,92 & 80,77 & 3,85 & 11,54 & 15,38 & 3,85 & 87,88 & 0,00 & 87,88 & 3,03 & 3,03 & 7,69 & 7,69 & 100 \\
\hline
\end{tabular}


Quanto à avaliação, feita pelos enfermeiros, sobre o instrumento de registro utilizado na recuperação pós-anestésica, no Hospital I, 24 enfermeiros $(92,31 \%)$ concordam com a afirmação de que o instrumento auxilia no planejamento do cuidado, destes, $13(50,00 \%)$ concordam plenamente e $11(42,31 \%)$ parcialmente; $21(80,77 \%)$ concordam com a afirmação de que o instrumento é um meio de documentar o cuidado, destes, $14(53,85 \%)$ concordam plenamente e $7(26,92 \%)$ parcialmente; $20(76,92 \%)$ concordam com a afirmação de que o instrumento de registro promove a continuidade do cuidado, destes, $15(57,69 \%)$ concordam plenamente e $5(19,23 \%)$ parcialmente; $16(61,54 \%)$ concordam com a afirmação de que o instrumento é um meio de comunicação, destes, $9(34,62 \%)$ concordam plenamente e $7(26,92 \%)$ parcialmente e, por último, 15 enfermeiros $(57,69 \%)$ concordam com a afirmação de que o instrumento é um indicador de qualidade, destes, $8(30,77 \%)$ concordam plenamente e 7 (26,92\%) parcialmente. No Hospital II, obteve-se a mesma freqüência às afirmações de que o instrumento auxilia no planejamento do cuidado, promove a continuidade e é um meio de documentar o cuidado, visto que 29 enfermeiros $(87,88 \%)$ concordam com essas afirmações, variando, apenas, em concordância plena ou parcial. Além disso, 26 enfermeiros (78,79\%) concordam com a afirmação de que o instrumento é um meio de comunicação, destes, $18(54,55 \%)$ concordam plenamente e $8(24,24 \%)$ parcialmente e, por fim, $25(75,76 \%)$ concordam com a afirmação de que o instrumento é um indicador de qualidade, destes, $24(72,73 \%)$ concordam plenamente e $1(3,03 \%)$ parcialmente.

Apesar dos enfermeiros concordarem de uma forma ou de outra que o instrumento de registro auxilia no planejamento da assistência, promove a 
continuidade do cuidado, é um indicador de qualidade, é um meio de comunicação e de documentação do cuidado, é representativo o número de enfermeiros, 18 $(69,23 \%)$ no Hospital I e $12(36,36 \%)$ no Hospital II, que não o consultam como mostram os dados da Tabela 5. Em seguida, esses mesmos enfermeiros, relataram os motivos pelos quais não consultam esse instrumento (Tabela 7) e os dados clínicos que utilizam para planejar a assistência ao paciente cirúrgico (Quadro I), já que não consultam o instrumento de registro da recuperação pós-anestésica. Com relação aos enfermeiros que se utilizam do registro, eles avaliaram os dados clínicos como mostra a Tabela 6.

Tabela 5 - Distribuição dos enfermeiros segundo consulta ao instrumento de registro da recuperação pós-anestésica. São Paulo - 2005.

\begin{tabular}{lccccccc}
\hline \multirow{2}{*}{ Enfermeiros } & \multicolumn{2}{c}{ Hospital I } & \multicolumn{2}{c}{ Hospital II } & \multicolumn{2}{c}{ Global } \\
\cline { 2 - 8 } & $\mathbf{n}$ & $\boldsymbol{\%}$ & $\mathbf{n}$ & $\mathbf{\%}$ & $\mathbf{n}$ & $\boldsymbol{\%}$ \\
\hline Consultam & 8 & 30,77 & 21 & 63,64 & 29 & 49,15 \\
Não Consultam & 18 & 69,23 & 12 & 36,36 & 30 & 50,85 \\
\hline Total & $\mathbf{2 6}$ & $\mathbf{1 0 0}$ & $\mathbf{3 3}$ & $\mathbf{1 0 0}$ & $\mathbf{5 9}$ & $\mathbf{1 0 0}$ \\
\hline
\end{tabular}


Tabela 6 - Distribuição da importância dos dados clínicos segundo avaliação dos enfermeiros que consultam o instrumento de registro da recuperação pós-anestésica. São Paulo, 2005.

\begin{tabular}{|c|c|c|c|c|c|c|c|c|c|c|c|c|c|c|}
\hline \multirow[t]{2}{*}{ Dados Clínicos } & \multicolumn{6}{|c|}{ Hospital I } & \multicolumn{6}{|c|}{ Hospital II } & \multicolumn{2}{|c|}{ Total } \\
\hline & 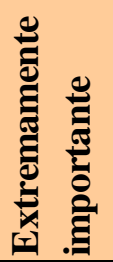 & 兽 & 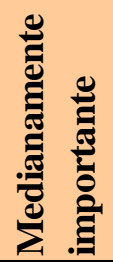 & ¿ & Z & 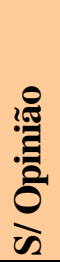 & 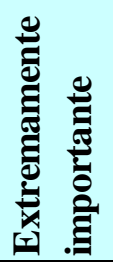 & 总 & 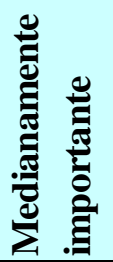 & 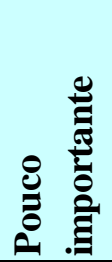 & 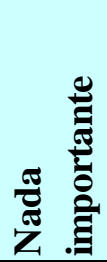 & 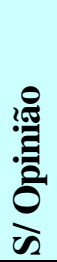 & $\mathbf{N}^{\mathbf{o}}$ & $\%$ \\
\hline Cirurgia & 7 & 1 & 0 & 0 & 0 & 0 & 18 & 3 & 0 & 0 & 0 & 0 & 29 & 100 \\
\hline Anestesia & 8 & 0 & 0 & 0 & 0 & 0 & 16 & 5 & 0 & 0 & 0 & 0 & 29 & 100 \\
\hline $\mathrm{T}^{\mathrm{o}}$ & 4 & 3 & 1 & 0 & 0 & 0 & 17 & 4 & 0 & 0 & 0 & 0 & 29 & 100 \\
\hline $\mathrm{P}$ & 4 & 4 & 0 & 0 & 0 & 0 & 18 & 3 & 0 & 0 & 0 & 0 & 29 & 100 \\
\hline $\mathrm{R}$ & 5 & 3 & 0 & 0 & 0 & 0 & 17 & 3 & 0 & 1 & 0 & 0 & 29 & 100 \\
\hline PA & 5 & 3 & 0 & 0 & 0 & 0 & 20 & 1 & 0 & 0 & 0 & 0 & 29 & 100 \\
\hline $\mathrm{SaO}_{2}$ & 5 & 3 & 0 & 0 & 0 & 0 & 17 & 4 & 0 & 0 & 0 & 0 & 29 & 100 \\
\hline Nível Consciência & 7 & 1 & 0 & 0 & 0 & 0 & 21 & 0 & 0 & 0 & 0 & 0 & 29 & 100 \\
\hline Atividade & 5 & 0 & 3 & 0 & 0 & 0 & 18 & 2 & 0 & 0 & 1 & 0 & 29 & 100 \\
\hline Coloração & 5 & 3 & 0 & 0 & 0 & 0 & 15 & 6 & 0 & 0 & 0 & 0 & 29 & 100 \\
\hline Curativos & 5 & 3 & 0 & 0 & 0 & 0 & 18 & 3 & 0 & 0 & 0 & 0 & 29 & 100 \\
\hline Drenos & 6 & 2 & 0 & 0 & 0 & 0 & 20 & 1 & 0 & 0 & 0 & 0 & 29 & 100 \\
\hline Cateteres & 5 & 2 & 1 & 0 & 0 & 0 & 20 & 1 & 0 & 0 & 0 & 0 & 29 & 100 \\
\hline Sondas & 5 & 2 & 1 & 0 & 0 & 0 & 19 & 2 & 0 & 0 & 0 & 0 & 29 & 100 \\
\hline Ostomias & 5 & 2 & 1 & 0 & 0 & 0 & 17 & 2 & 1 & 1 & 0 & 0 & 29 & 100 \\
\hline Balanço Hídrico & 6 & 1 & 1 & 0 & 0 & 0 & 13 & 4 & 2 & 2 & 0 & 0 & 29 & 100 \\
\hline Medicações & 6 & 0 & 2 & 0 & 0 & 0 & 16 & 5 & 0 & 0 & 0 & 0 & 29 & 100 \\
\hline Intercorrências & 7 & 1 & 0 & 0 & 0 & 0 & 21 & 0 & 0 & 0 & 0 & 0 & 29 & 100 \\
\hline Outros* & & & & & & & & & & & & & & \\
\hline
\end{tabular}

* Hos pital I: Perfusão periférica; presença de petéquias no corpo 
Tabela 7 - Distribuição dos motivos pelos quais o instrumento de registro da recuperação pós-anestésica não é consultado. São Paulo - 2005.

\begin{tabular}{|c|c|c|c|c|c|c|}
\hline \multirow[t]{2}{*}{ Motivo } & \multicolumn{2}{|c|}{ Hospital I } & \multicolumn{2}{|c|}{ Hospital II } & \multicolumn{2}{|c|}{ Global } \\
\hline & $\mathbf{n}$ & $\%$ & $\mathbf{n}$ & $\%$ & $\mathbf{n}$ & $\%$ \\
\hline Falta de tempo & 0 & 0,00 & 1 & 8,33 & 1 & 3,33 \\
\hline Cópia ilegível & 0 & 0,00 & 0 & 0,00 & 0 & 0,00 \\
\hline Informações não compreensíveis & 0 & 0,00 & 0 & 0,00 & 0 & 0,00 \\
\hline Não precisa das informações da RPA & 0 & 0,00 & 1 & 8,33 & 1 & 3,33 \\
\hline Instrumento complicado & 0 & 0,00 & 0 & 0,00 & 0 & 0,00 \\
\hline Avaliação no momento da admissão* & 18 & 100,00 & 4 & 33,33 & 22 & 73,33 \\
\hline Outros** & 0 & 0,00 & 6 & 50,00 & 6 & 20,00 \\
\hline Total & 18 & 100 & 12 & 100 & 30 & 100 \\
\hline
\end{tabular}

* Hospital I: Os 18 enfermeiros que não consultam o instrumento de registro da recuperação anestésica alegaram avaliar o paciente no momento da admissão por desconhecer o instrumento.

** Hospital II: inclui profissionais que associaram mais de um motivo. 
Quadro 1 - Distribuição dos dados clínicos utilizados pelos enfermeiros, no período pós operatório, que não se utilizam do instrumento de registro da recuperação pós-anestésica para dar continuidade à assistência ao paciente cirúrgico.São Paulo - 2005.

\begin{tabular}{|c|c|c|c|c|c|c|}
\hline \multirow[t]{2}{*}{ Parâmetros Clínicos } & \multicolumn{2}{|c|}{ Hospital I } & \multicolumn{2}{|c|}{ Hospital II } & \multicolumn{2}{|c|}{ Global } \\
\hline & $\mathbf{n}$ & $\%$ & $\mathbf{n}$ & $\%$ & $\mathrm{n}$ & $\%$ \\
\hline * Sinais vitais & 9 & 6,08 & 3 & 14,29 & 12 & 7,10 \\
\hline * Curativos & 16 & 10,81 & 2 & 9,52 & 18 & 10,65 \\
\hline * Prescrição médica & 4 & 2,70 & 1 & 4,76 & 5 & 2,96 \\
\hline * Nível de consciência & 14 & 9,46 & 0 & 0,00 & 14 & 8,28 \\
\hline * Sondas & 12 & 8,11 & 1 & 4,76 & 13 & 7,69 \\
\hline * Sinais e sintomas & 1 & 0,68 & 0 & 0,00 & 1 & 0,59 \\
\hline * Coloração / Perfusão & 4 & 2,70 & 1 & 4,76 & 5 & 2,96 \\
\hline * Drenos & 15 & 10,14 & 3 & 14,29 & 18 & 10,65 \\
\hline * Acesso venoso & 8 & 5,41 & 0 & 0,00 & 8 & 4,73 \\
\hline * Tempo de duração da cirurgia & 1 & 0,68 & 0 & 0,00 & 1 & 0,59 \\
\hline * Transfusão & 2 & 1,35 & 0 & 0,00 & 2 & 1,18 \\
\hline * Anestesia & 4 & 2,70 & 1 & 4,76 & 5 & 2,96 \\
\hline * Movimentos / Atividade & 2 & 1,35 & 1 & 4,76 & 3 & 1,78 \\
\hline * Necessidade de acompanhante & 2 & 1,35 & 0 & 0,00 & 2 & 1,18 \\
\hline * Dor & 6 & 4,05 & 1 & 4,76 & 7 & 4,14 \\
\hline * Sangramentos & 6 & 4,05 & 0 & 0,00 & 6 & 3,55 \\
\hline * Náusea / Vômito & 3 & 2,03 & 0 & 0,00 & 3 & 1,78 \\
\hline * Liberação da dieta & 3 & 2,03 & 0 & 0,00 & 3 & 1,78 \\
\hline * Estado geral (aparência) & 2 & 1,35 & 0 & 0,00 & 2 & 1,18 \\
\hline * Pupila & 1 & 0,68 & 0 & 0,00 & 1 & 0,59 \\
\hline * Cirurgia & 3 & 2,03 & 0 & 0,00 & 3 & 1,78 \\
\hline * Colostomia & 2 & 1,35 & 0 & 0,00 & 2 & 1,18 \\
\hline * Estado psicológico & 1 & 0,68 & 0 & 0,00 & 1 & 0,59 \\
\hline * Exames & 3 & 2,03 & 0 & 0,00 & 3 & 1,78 \\
\hline * Hidratação & 1 & 0,68 & 0 & 0,00 & 1 & 0,59 \\
\hline * Ausculta cardíaca / Pulmonar / Abdominal & 1 & 0,68 & 0 & 0,00 & 1 & 0,59 \\
\hline * PAM & 1 & 0,68 & 0 & 0,00 & 1 & 0,59 \\
\hline * Padrão respiratório & 4 & 2,70 & 0 & 0,00 & 4 & 2,37 \\
\hline * Ventilação mecânica & 3 & 2,03 & 0 & 0,00 & 3 & 1,78 \\
\hline * Ganhos / Perdas & 3 & 2,03 & 0 & 0,00 & 3 & 1,78 \\
\hline * Cateteres & 3 & 2,03 & 1 & 4,76 & 4 & 2,37 \\
\hline * PVC & 1 & 0,68 & 0 & 0,00 & 1 & 0,59 \\
\hline * PIC & 1 & 0,68 & 0 & 0,00 & 1 & 0,59 \\
\hline * Monitorização & 1 & 0,68 & 0 & 0,00 & 1 & 0,59 \\
\hline * Aspiração & 1 & 0,68 & 0 & 0,00 & 1 & 0,59 \\
\hline * Oxímetro / $\mathrm{SaO}_{2}$ & 1 & 0,68 & 2 & 9,52 & 3 & 1,78 \\
\hline * Anotações & 2 & 1,35 & 0 & 0,00 & 2 & 1,18 \\
\hline * Intercorrências & 1 & 0,68 & 0 & 0,00 & 1 & 0,59 \\
\hline$*$ SAE & 0 & 0,00 & 1 & 4,76 & 1 & 0,59 \\
\hline * Exame físico & 0 & 0,00 & 2 & 9,52 & 2 & 1,18 \\
\hline * Forma holística & 0 & 0,00 & 1 & 4,76 & 1 & 0,59 \\
\hline Total & 148 & 100 & 21 & 100 & 169 & 100 \\
\hline
\end{tabular}

*Foram reproduzidas as expressões utilizadas pela população em estudo. 
Como podemos observar, os dados das Tabelas 5, 6, 7 e do Quadro I trazem informações complementares, evidenciando que dos 26 (100\%) enfermeiros do Hospital I, 18 (69,23\%) não consultam o instrumento de registro da recuperação pós-anestésica (Tabela 5), pois alegaram não conhecer este instrumento, avaliando, portanto, o paciente no momento da admissão (Tabela 7). Dentre os dados clínicos utilizados por estes destacaram-se: características dos curativos e drenos, nível de consciência, controle das sondas, sinais vitais e acesso venoso (Quadro I). Quanto aos $8(30,77 \%)$ enfermeiros que consultavam este registro, verificou-se que a maioria classificou os dados clínicos, como extremamente importante, somente os parâmetros referentes à temperatura e pulso apresentaram diferenças de opinião quanto ao nível de importância (extremamente importante e muito importante) - Tabela 6. Já no Hospital II, dos 33 (100\%) enfermeiros entrevistados, 12 (36,36\%) não consultavam o instrumento de registro da recuperação pós-anestésica (Tabela 5). Considerando esses 12 enfermeiros como (100\%) da amostra, observou-se que 6 (50,00\%) alegaram não consultar devido à associação dos diversos motivos presentes na Tabela 7 ou simplesmente alegaram outros motivos não contemplados na tabela em questão e os outros $6(50,00 \%)$ ficaram divididos entre: avaliar o paciente no momento da admissão $4(33,33 \%)$; por falta de tempo $1(8,33 \%)$ e por não precisar das informações do período de recuperação pós-anestésica 1 (8,33\%) - (Tabela 7). Dentre os dados utilizados, por àqueles que não consultavam o instrumento, ou seja, avaliavam o paciente no momento da admissão, destacaram-se sinais vitais e características dos drenos, seguidos de curativos, saturação de oxigênio e exame físico (Quadro I). Em relação aos $21(63,64 \%)$ que consultavam este registro, 
Elaine Reda

observou-se que a maioria classificou os dados clínicos presentes na Tabela 6 como extremamente importantes. 


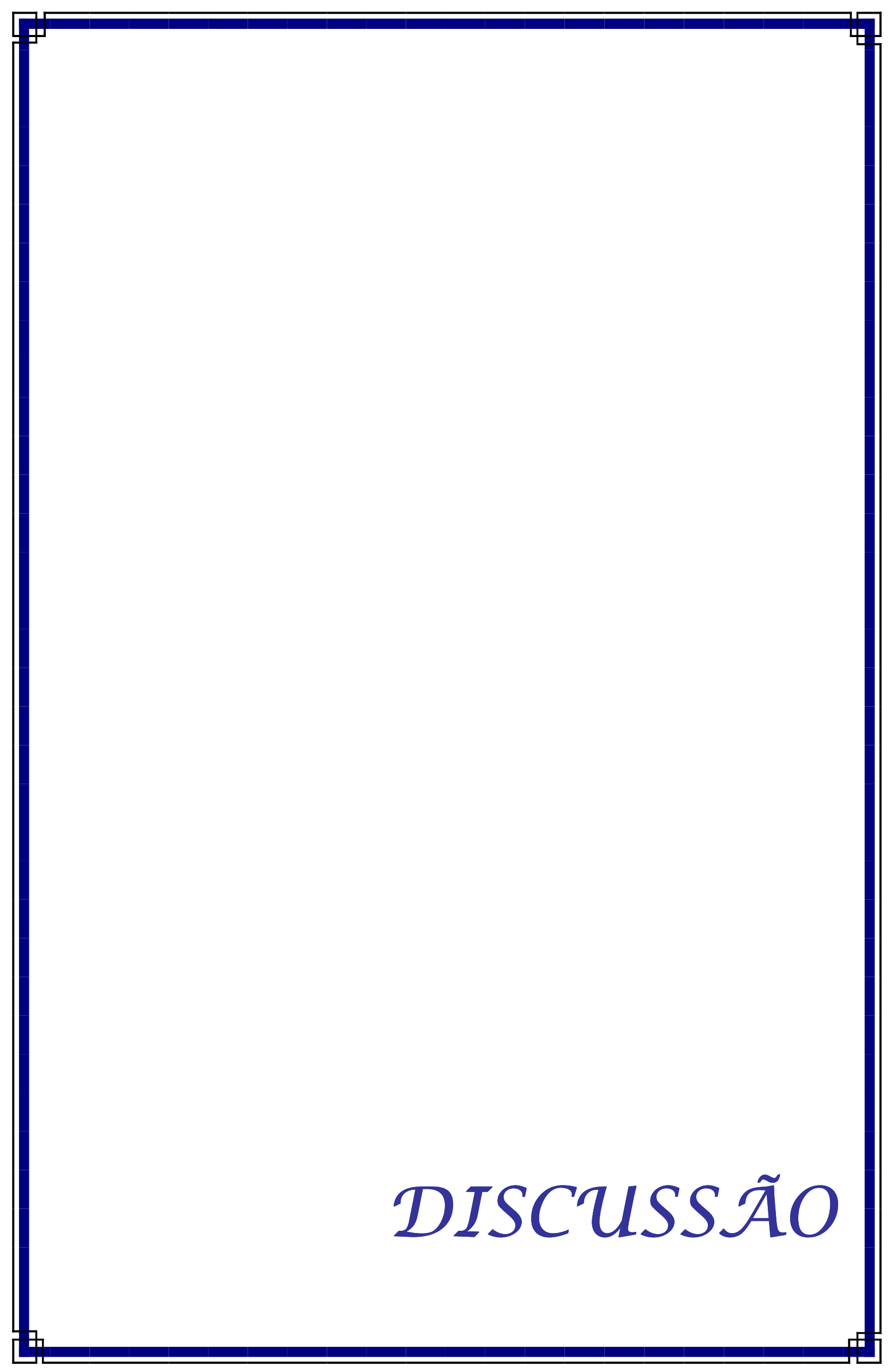




\section{DISCUSSÃO}

A busca pela especificidade do cuidar relacionado ao paciente parece determinar uma das características da amostra aqui estudada, uma vez que a maioria dos enfermeiros, embora, recém formados, apresenta-se como especialista em cuidar do paciente crítico. Esta prevalência pode ser também um reflexo da diminuição de carga horária nos cursos de graduação no que se refere ao conteúdo programático relacionado a este perfil de paciente, ou ainda, a possibilidade de desenvolver a habilidade manual tão desejada pelos enfermeiros no início de sua atividade profissional.

$\mathrm{Na}$ busca do preenchimento das lacunas deixadas pelo curso de graduação de enfermagem, o profissional tem utilizado como estratégia os cursos de especialização lato sensu, propostos a prestar uma assistência criativa, e a contribuir para uma formação crítica, reflexiva e competente, necessária nesta área de atuação.

Com relação às dificuldades apresentadas pelos enfermeiros em obter dados clínicos dos pacientes, referentes ao período de recuperação pós-anestésica (Tabela 2), observa-se que em ambos os hospitais as mesmas estão relacionadas à comunicação escrita e verbal. No Hospital II, porém, onde o sistema de assistência já se encontra implantado, todas as dificuldades se apresentam com frequiências superiores a 50,00\%, distribuídas em diferentes níveis de intensidade, destacando-se, por exemplo, no nível de intensidade "muitas vezes", o instrumento sem as informações necessárias com uma freqüência de 39,39\%, o instrumento preenchido de forma incompleta com 33,33\% e ausência do instrumento no prontuário com 24,24\%, e no nível de intensidade "sempre", a ausência da passagem de plantão por 
telefone com uma freqüência de $36,36 \%$, e a passagem incompleta de plantão por telefone, $30,30 \%$.

Acredita-se que com a implantação do SAE estas ocorrências não existissem ou fossem menores, pois subentende-se que com a criação de um instrumento esta premissa, isto é, a continuidade do cuidado, fosse atingida.

Entende-se, portanto, que não basta a criação de um instrumento, é necessário o registro correto das informações.

Perez e et al. ${ }^{(47)}$ ressaltam a necessidade de registro de todos os cuidados de enfermagem oferecidos para se atingir a continuidade da assistência e para ser possível avaliar a assistência prestada, uma vez que serve como base para apreciar a qualidade dos cuidados, melhorando o desempenho dos profissionais, sistematizando e uniformizando as ações e fornecendo dados úteis para pesquisa, educação e planejamento. Essas mesmas autoras relatam que o registro das informações preenche outras finalidades, ou seja, serve como registro dos serviços e assuntos legais para o hospital e para a equipe de profissionais responsáveis pelos cuidados dos pacientes. Destacam ainda que, o simples preenchimento de uma folha de registro não melhora por si só a assistência, mas proporciona à enfermagem um meio para documentar suas ações, as quais estão baseadas em método científico e não em intuição e que, nos registros, os cuidados de enfermagem nem sempre são relatados de forma consistente visto que, em geral, limitam-se às demonstrações gráficas de tarefas e rotinas, funções componentes da prática de enfermagem.

Uma vez apontadas as dificuldades de ambas as instituições em obter os dados clínicos, constata-se que os enfermeiros envolvidos citam o instrumento de registro da recuperação pós anestésica e a passagem de plantão por telefone como as 
melhores estratégias para obtenção dos mesmos (tabela 3), o que de certa forma coincide com as dificuldades anteriormente apresentadas. Parece existir uma incoerência nestes resultados. Isto significa dizer que as dificuldades são concretas e que as ferramentas, embora corretas, não funcionam adequadamente.

Este fato é confirmado quando, em ambas as instituições estudadas (Tabela 4), os enfermeiros avaliam o instrumento de registro como uma das estratégias escolhidas mais eficiente para dar continuidade à assistência e um espaço correto para a documentação do cuidado. Porém as informações são incompletas, não retratando as reais condições do paciente e pouco contribuindo como um indicador de qualidade, demonstrando ser um meio de comunicação ineficiente.

Kron, Gray ${ }^{(48)}$; Teixeira, Prates, Almeida ${ }^{(49)}$, afirmam que os registros de enfermagem são importantes para acompanhar a evolução do paciente, além de comprovar a assistência prestada e cumprir exigências legais. Outro aspecto destacado é serem utilizados como fonte de informação para o processo de auditoria quer no aspecto contábil quer na avaliação da qualidade dos cuidados de enfermagem prestados, além de ser uma fonte de dados para a realização de pesquisas. Contudo, em geral, as anotações dizem respeito ao cumprimento da terapia médica e às técnicas gerais de enfermagem, quando, na verdade, além deste conteúdo, deveriam ter a resposta do paciente aos objetivos da intervenção de enfermagem quando estabelecidos.

Segundo Zanon ${ }^{(50)}$, é inadmissível considerar uma assistência de boa qualidade quando os registros médicos e de enfermagem não existem ou são incompletos. 
Algumas pesquisas realizadas demonstram a importância das anotações e a dificuldade destas traduzirem todas as ações praticadas pelos profissionais de enfermagem e, dentre elas, destaca-se o estudo de Pádua ${ }^{(51)}$, que constatou em uma unidade cirúrgica de um hospital universitário de Campo Grande-MS, que as anotações de enfermagem não possuíam sistematização que atendesse ao processo de enfermagem, prevalecendo anotações relativas à terapêutica clínica-cirúrgica em detrimento das demais, com tendência ainda para o modelo assistencial biomédico. Verificou também, a presença de registros factuais, aleatórios, redundantes, subjetivos, incorretos tecnicamente e desprovidos de qualquer sistemática que pudesse subsidiar o planejamento dos cuidados de enfermagem. Concluiu-se que, as anotações não atendem às necessidades apresentadas pelos pacientes, tornando os registros de enfermagem, documentos técnicos e legais frágeis no âmbito ético e jurídico, sendo estes aspectos preocupantes quanto à qualidade do conteúdo, se for necessário sua utilização na justiça.

Fávero $^{(52)}$, fazendo um estudo descritivo das anotações de enfermagem de pacientes internados num hospital escola governamental, utilizando um corte transversal, através de observação direta das atividades de enfermagem e respectivas anotações, verificou que das atividades de enfermagem executadas durante a investigação, quase a metade (41,53\%) não foi anotada. E salienta que uma porcentagem alta de atividade desempenhada não anotada coube ao enfermeiro $(58,63 \%)$.

Dalri, Rossi e Carvalho ${ }^{(53)}$ realizaram um estudo retrospectivo dos registros de enfermagem em 12 prontuários de doadores de órgãos, de um hospital universitário do interior do Estado de São Paulo, e verificaram que em 50\% dos 
prontuários não foram encontrados registros de avaliação pela enfermagem após a cirurgia, informando sobre a ausência dos sinais vitais ou sobre o estado do paciente. No período transoperatório, as anotações analisadas foram consideradas incompletas em $100 \%$ dos prontuários, faltava início e término da anestesia e cirurgia, colocação de placa do bisturi, posição do paciente na mesa de operação e instalação de equipamentos. Somente em 16,7\% dos prontuários encontraram informações sobre o encaminhamento do órgão, e apenas 8,3\% especificaram o local para onde o órgão foi encaminhado. Observaram ainda que em $91,7 \%$ dos prontuários faltavam a data e a assinatura nas anotações de enfermagem, além de rasuras.

Na pesquisa realizada por Johanson et al ${ }^{(54)}$, em um hospital universitário do Rio de Janeiro, sobre o registro de enfermagem, especialmente sua importância no controle e prevenção da infecção relacionada a cateter venoso em clientes com HIV/AIDS, verificou-se que a equipe de enfermagem registra apenas os sinais vitais, o tipo de acesso, a medicação infundida, a localização do acesso e o tipo de cateter utilizado. Foi constatado também que as anotações, em sua maioria, eram feitas por técnicos, auxiliares e estagiários de enfermagem do nível médio. Tais registros eram repetitivos e relatavam aspectos superficiais, não mencionando, por exemplo, condições do curativo, os sinais flogísticos e as complicações locais, o que pode comprometer sua função comunicativa na prevenção e controle da infecção relacionada ao cateter venoso. Resumidamente, os registros sinalizam apenas a realização da punção venosa e a manutenção do acesso, não abrangendo as questões mais específicas do paciente.

Araújo ${ }^{(55)}$, em um estudo realizado com 50 enfermeiros associados à Sociedade Brasileira de Enfermeiros de Centro Cirúrgico (SOBECC) e enfermeiros 
do IX Curso de Especialização em Enfermagem em Centro Cirúrgico da Universidade de São Paulo (USP) - 2003, atuantes em centro cirúrgico, identificou o evento adverso de maior incidência no período transoperatório, constatando que a anotação inadequada em prontuário é o de maior incidência (60\%).

Outra pesquisa, realizada por Labbadia, Adami ${ }^{(56)}$, identificou aspectos quantitativos e qualitativos das anotações de enfermagem nos prontuários dos pacientes internados em um hospital universitário; comparou as anotações de enfermagem registradas nos prontuários de pacientes da unidade de treinamento admissional com as de outras unidades de internação e avaliou estes dados confrontando-os com o princípio orientador do padrão do nível 1 do Manual Brasileiro de Acreditação Hospitalar (MBAH) estabelecido para a Subseção Enfermagem. A referida pesquisa obteve, como resultado, após verificar 130 prontuários de pacientes internados no referido hospital, que as atividades relacionadas à execução da prescrição médica tais como - terapêutica medicamentosa, controle de sinais vitais e outros controles - foram registradas na forma completa, na maioria dos prontuários avaliados. $\mathrm{O}$ desempenho da equipe de enfermagem da unidade de treinamento foi superior ao das outras unidades apenas em relação aos registros de saída - alta. No confronto dos dados com o princípio orientador do Nível 1 do MBAH, verificou-se que os itens relacionados aos controles dos pacientes e da legibilidade das anotações foram os únicos que apresentaram valores superiores a 90\%. Conclui-se que as atividades de enfermagem realizadas nesta instituição estavam voltadas, ainda, para a execução das prescrições médicas; as anotações foram descritas de forma incompleta e fragmentada, impossibilitando a identificação de aspectos mínimos de condutas de enfermagem que visam a 
segurança e a continuidade da assistência ao paciente internado, comprometendo assim, os aspectos éticos e legais da documentação.

Janúncio $^{(57)}$, em sua dissertação de mestrado, confirmou sua hipótese de que a anotação da sistematização não estava atendendo adequadamente a continuidade da assistência ao paciente cirúrgico à medida que constatou que os dados estavam incompletos e não garantiam uma observação integral de cada paciente e para todos os pacientes, realizadas por cada profissional de enfermagem, envolvido na assistência perioperatória. Após a análise, certificou-se que dados importantes para o paciente, no período, poderiam ter sido ou não avaliados e as anotações deixavam dúvidas sobre estas avaliações, considerando que as anotações de enfermagem não refletiam ou não valorizavam o trabalho e a assistência de enfermagem no período perioperatório.

Apesar da importância, a documentação das intervenções é um dos componentes mais deficientes no processo de assistência de enfermagem. As causas subjacentes deste problema estão relacionadas com a escassez de prestadores de cuidados em relação às necessidades dos pacientes; com a falta de tempo para registrar de forma detalhada a assistência proporcionada; com a carência de formas estruturadas da coleta de dados e de um sistema integrado para o processamento e a recuperação destes ${ }^{(58)}$.

O sistema de informação em saúde é, segundo Kurcgant ${ }^{(59)}$ :

o instrumento utilizado no processo de planejamento, aperfeiçoamento e tomada de decisão nas diversas instâncias da organização e gerência dos serviços de saúde, contemplando ainda os estudos necessários às questões relativas aos fatores predisponentes, portadores ou mantenedores de enfermidades. 
Os registros em prontuário e a passagem de plantão são recursos fundamentais para a comunicação efetiva. Somente através da informação qualitativa, ou seja, informação com exatidão e atualizada, é possível desenvolvermos um processo de tomada de decisão que reverta em benefício do cliente, da empresa e do funcionário.

É importante salientar que os registros claros, exatos e precisos permitem a comunicação entre a equipe de saúde, a avaliação da terapêutica, a auditoria e a investigação científica, entre outras. Além destes, merece ser destacado a importância dos registros quanto ao seu valor legal na apuração de responsabilidades assim como na transparência da contabilidade e custos dos processos hospitalares.

Apesar de todas estas considerações, os dados das Tabelas 5 e 7 mostram respectivamente que um número de enfermeiros representativo tanto no Hospital I (18) como no Hospital II (12), sendo que neste último existe o SAE implantado, não consultam o instrumento e apontam como motivos a preferência em avaliar o paciente no momento da chegada na clínica de origem, ou seja, desconsideram todas as informações do período perioperatória, uma vez que a inexistência da passagem de plantão por telefone também foi pontuada pelos enfermeiros, em ambos os hospitais, com valores expressivos (Tabela 2).

Ressalta-se que os enfermeiros do Hospital I, que não utilizam o instrumento de registro da recuperação pós-anestésica no momento da admissão do paciente, para a obtenção dos dados clínicos, justificam o não conhecimento deste instrumento embora o mesmo esteja em processo de implantação. Já no Hospital II, embora quatro enfermeiros relatem que avaliam o paciente no momento da admissão 
Elaine Reda

(Tabela 7), esta justificativa não seria pertinente, pois o instrumento já faz parte do prontuário.

Através dos registros em prontuário, a equipe de enfermagem documenta todas as ações desenvolvidas e descreve as reações e evolução do estado de saúde dos pacientes. $\mathrm{O}$ ato de registrar confere maior segurança, precisão e reflexão sobre as ações dirigidas executadas, além de ser um fator de proteção para a equipe e para o paciente em casos que necessitem uma investigação.

$\mathrm{Na}$ passagem de plantão, a enfermagem resgata os registros efetuados, avalia e corrige ações da assistência, assegurando a continuidade do cuidado e tratamento dos pacientes.

Utilizando estes recursos de comunicação, a enfermagem torna-se o elo integrador no sistema de informação em saúde, concentrando as informações a respeito do quadro do paciente e das ações que estão sendo implementadas pelas várias equipes de saúde, sendo a passagem de plantão o momento que permite a integração destes dados e o planejamento de medidas futuras.

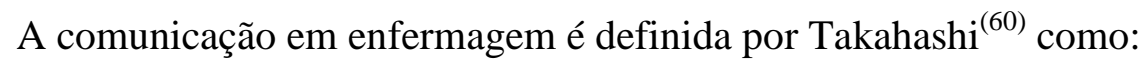

o processo pelo qual a equipe de enfermagem oferece e recebe informações do indivíduo, clientelpaciente, para planejar, executar, avaliar e participar com os demais membros da equipe de saúde, da assistência prestada no processo de saúdeldoença.

A importância da passagem de plantão é enfatizada por Daniel (61) quando afirma que:

uma passagem de plantão planejada é uma das partes essenciais da administração eficiente. Apesar de ser uma forma rápida de transmitir, receber e delegar atribuições, poderá levar o grupo a funcionar 
cooperativamente, contribuindo para um melhor atendimento de enfermagem.

Magalhães, Pires, Keretzky ${ }^{(62)}$ buscaram as respostas a respeito das opiniões que os enfermeiros, das unidades de internação cirúrgica do Hospital das Clínicas de Porto Alegre evidenciaram a respeito da passagem de plantão e como isto repercutiu na organização do seu trabalho e no processo de cuidar em enfermagem. Puderam também registrar que, para estes enfermeiros, a mesma é uma atividade fundamental para a organização do trabalho na unidade, sendo um fator decisivo para manter a qualidade dos cuidados prestados, pois permite a atualização das informações sobre o paciente e a adequação das ações de enfermagem. Os enfermeiros expressaram ainda que, a passagem de plantão é importante, mas identificaram aspectos que dificultam esta atividade e que não vêm sendo discutidos na instituição, o que acarreta uma prática que não corresponde ao que é preconizado pela instituição. Assim, as autoras concluem que a passagem de plantão é um elemento essencial para o trabalho do enfermeiro e que há necessidade de avaliar e discutir esta atividade no sentido de valorizá-la e enriquecê-la, com vistas a se obter melhores resultados e assegurar uma assistência de enfermagem de qualidade e livre de riscos ao cliente. Acreditam ainda que uma das formas para aprimorar esse processo seja investir em transformar este momento, não apenas em transmissão de informações, mas também num momento educativo que proporcione o encontro, a integração e o crescimento mútuo da equipe.

Dentre os resultados da pesquisa de Leite ${ }^{(29)}$, pode-se verificar que dos 11 enfermeiros da unidade de internação, 7 (61,11\%) relatam existir algum tipo de intercâmbio de informações entre os enfermeiros da unidade de internação com os enfermeiros do centro cirúrgico. Esse intercâmbio se caracterizava por uma 
comunicação verbal e escrita. Em relação ao intercâmbio de informações estabelecido entre os enfermeiros do centro cirúrgico e os enfermeiros da unidade de internação, ficou demonstrado que $8(66,67 \%)$ enfermeiros do centro cirúrgico mantinham intercâmbio verbal, por telefone, com os enfermeiros da unidade de internação, porém, essa comunicação só acontecia em algumas situações.

Andrade et al. ${ }^{(63)}$ realizaram uma pesquisa buscando identificar os fatores que interferem na comunicação dos enfermeiros durante a passagem de plantão, bem como as consequiências da falta de comunicação em hospitais públicos e privados de Aracajú. Dentre as dificuldades referidas na passagem de plantão, emergiram a ausência da comunicação direta, a falta de clareza dos registros, o pouco tempo dispensado para a mesma, a documentação insuficiente e a não valorização desta atividade. Essas dificuldades contribuíram, segundo a percepção dos respondentes, para o aparecimento de problemas de natureza administrativa e de assistência direta como: mal-entendidos, reprogramação de exames, desconhecimento de informações a respeito do plantão anterior, omissão de informações sobre a gravidade dos clientes e comprometimento de transferência de pacientes para outros hospitais. Apesar dos respondentes terem ciência dos problemas e saberem identificar os fatores que comprometem essa comunicação, eles não conseguem implementar estratégias para a correção destes, sendo assim, esta comunicação foi qualificada de insuficiente, necessitando, portanto, de sérios ajustes na sua operacionalização. Este estudo possibilitou a elaboração de sugestões para uma prática eficaz da passagem de plantão, dentre elas: a normatização desta atividade nas instituições que ainda não a têm, a sistematização da comunicação na forma escrita, a comunicação de objetivos entre os profissionais enfermeiros para a garantia da qualidade de assistência e o 
estabelecimento de uma escala de valores no que se refere à prioridade das informações. As autoras ressaltaram ainda, que a passagem de plantão, quando realizada de forma efetiva, pode trazer enormes benefícios para a instituição, para o paciente e para todos os profissionais envolvidos garantindo assim, a continuidade do cuidado. Concluindo, percebe-se que a sistematização da comunicação nesta atividade é uma estratégia de melhoramento nas relações interpessoais no ambiente de trabalho, respeito mútuo entre os enfermeiros e também um instrumento facilitador na prestação da assistência de enfermagem.

A avaliação da qualidade em serviços de saúde tem se tornado um assunto cada vez mais freqüente face à importância da adequação destes às necessidades dos usuários. Portanto, faz-se necessário, cada vez mais, desenvolver novas propostas e métodos que permitam gerenciar os processos de trabalho e recursos relacionados a esta assistência.

Segundo Nogueira ${ }^{(64)}$, na área da saúde, a qualidade não deve ser vista como uma substância ou coisa em si, mas uma referência resultante das formas inerentes ao processo de produção dos serviços. Assim, questões sobre a qualidade do processo de prestação de serviços deveriam desencadear reflexões em grupos de trabalho, permitindo identificar e dissecar a dinâmica de alguns processos, sendo que esta discussão irá aclarar a estratégia a ser adotada para alcançar a qualidade. Dessa forma, a qualidade significa algo que os envolvidos nas ações de saúde estarão constantemente preocupados em aferir para dar maior satisfação aos que necessitam desses serviços.

Assim, Monte, Adami e Barros ${ }^{(65)}$ realizaram um estudo com os objetivos de identificar padrões indicadores e métodos utilizados na avaliação da assistência de 
enfermagem prestada em hospitais gerais de grande e extra porte no Município do Estado de São Paulo e, identificaram as dificuldades existentes para desenvolver e aprimorar os processos de sistematização e avaliação da assistência de enfermagem nestes hospitais. O campo de estudo foi constituído por 18 hospitais das redes pública e privada e as principais conclusões foram:

- Dentre os 18 serviços de enfermagem estudados, em $11(61,1 \%)$ existiam padrões para avaliar a assistência de enfermagem que, na maioria das instituições, estão relacionados à prevenção de infecções hospitalares, seguidos dos referentes às ações de enfermagem. Estes foram elaborados por grupos de enfermeiras dos hospitais selecionados;

- A utilização de indicadores de avaliação foi identificada em 5 (27,8\%) dos 18 serviços de enfermagem estudados. Em três serviços de enfermagem de hospitais públicos, um apresentava indicadores referentes a padrões da assistência de enfermagem e dois, à ocorrência de feridas e cuidados na unidade de terapia intensiva. Nos dois serviços de enfermagem dos hospitais privados, que adotavam indicadores, estes se referiam a eventos adversos, sendo que os principais mensuravam: erro de medicação, queda do leito, condições do acesso venoso e ocorrências na transferência de pacientes entre unidades;

- A notificação de eventos adversos estava presente em $16(88,9 \%)$ dos serviços de enfermagem estudados e para a resolução de problemas, as enfermeiras tomavam as medidas necessárias, contando com o respaldo da enfermeira chefe e, em alguns casos, da Comissão de Ética da instituição hospitalar;

- No que tange aos métodos avaliativos adotados, a auditoria em enfermagem era desenvolvida por enfermeiras capacitadas para esta atividade, 
realizada em períodos pré-determinados, em $4(22,2 \%)$ dos 18 serviços de enfermagem estudados. A observação era realizada pela enfermeira responsável pela unidade durante as visitas de enfermagem, em 9 (50,0\%) dos serviços de enfermagem, de forma não sistematizada, tanto em relação ao método quanto à freqüência em que ocorria;

- A tríade - padrões de cuidados de enfermagem, processo de enfermagem e métodos avaliativos - foi identificada, somente em 4 (22,2\%) serviços de enfermagem estudados pertencentes a três hospitais privados e um público, indicando, assim, os componentes necessários para a avaliação da qualidade dos cuidados de enfermagem prestados.

- Segundo a opinião das chefes dos serviços de enfermagem estudados, as dificuldades para implantar ou aprimorar os processos de sistematização e avaliação da assistência de enfermagem relacionam-se, principalmente, nos hospitais públicos, no preparo inadequado da formação de enfermeiras, à carência de pessoal de enfermagem, à falta de tempo e de comprometimento, envolvimento e responsabilidade no exercício dessas profissionais.

Haddad $^{(66)}$, em sua tese de doutorado, que teve como objetivos específicos descrever a implementação do Programa de Qualidade Total e analisar os resultados das entrevistas, da observação do ambiente e da auditoria nas anotações de enfermagem realizadas em 2002, com pacientes internados em uma unidade médicocirúrgica masculina de um hospital universitário público, demonstrou que a equipe atingiu, na opinião do paciente, o índice de prestar uma assistência de enfermagem segura nos itens referentes à Higiene e Conforto Físico, Atividades Físicas, Sono e Repouso. Para os itens referentes à Segurança Física, Nutrição e Hidratação o nível 
de assistência apresentou-se adequada, mas para os itens de Eliminações e Necessidades Emocionais o índice de assistência foi limítrofe. Para os itens de Necessidades Espirituais e Sociais, os indicadores mostraram uma assistência sofrível, demonstrando a pequena atenção que a equipe presta a esses aspectos. A análise referente à observação do ambiente também demonstrou que a equipe alcançou níveis de assistência adequada nos itens de Eliminações e Utilização de Equipamentos. Para os itens Atividade Física e Segurança Física, a classificação da assistência foi segura, enquanto que para os itens de Higiene e Conforto Físico, a classificação da assistência permaneceu sempre limítrofe. Mas o índice mais crítico foi em relação ao item Oxigênio e Ventilação que sempre permaneceu em assistência sofrível. Quanto aos resultados das auditorias realizadas nas anotações de enfermagem observou-se que, embora a equipe apresentasse melhora no preenchimento dos impressos, nunca atingiu o padrão estabelecido. O modelo de controle de qualidade utilizado nesse estudo citado mostrou ser um instrumento valioso para identificar a qualidade da prática assistencial executada pela equipe.

Embora nenhum estudo anterior tenha sido realizado com relação à validade dos instrumentos de registros utilizados nas duas instituições em estudo, estes cumprem sua finalidade uma vez que são compostos por dados clínicos considerados, por vários autores, como necessários para avaliar o paciente no período de recuperação pós-anestésica, assim como contém informações pertinentes para dar continuidade à assistência de enfermagem ao paciente no período pós-operatório tardio.

Vários autores, como Steward ${ }^{(67)}$, Posso $^{(46)}$, Castãnos ${ }^{(68)}$, Peniche $^{(69)}$, pela vulnerabilidade em que os pacientes se encontram e pelas intercorrências serem 
comuns e freqüentes em um período considerado curto ( 3 a 4 horas), propõem, além do índice existente de Aldrete e Kroulik, a reestruturação nos instrumentos de registros utilizados, para que auxiliem o controle e, sobretudo, proporcionem uma avaliação segura e contínua das condições gerais dos pacientes na recuperação pósanestésica.

Cunha $^{(70)}$, em um estudo que teve como objetivos propor um instrumento de registro para avaliação do paciente em sala de recuperação pós-anestésica e validar seu conteúdo, relata que o instrumento proposto foi formulado com a finalidade de abranger todos os itens que devem ser observados no paciente em recuperação. Eles devem ser separados em sistemas, para que facilitem a equipe de enfermagem em sua atuação na recuperação anestésica, isto é, um guia do que deve ser sempre observado. Porém, em primeira análise feita pelos juízes, o instrumento mostrou-se com muitos itens e também repetitivo, levando-os ao questionamento do tempo hábil para seu correto preenchimento. Após esta primeira análise, com a técnica Delphi utilizada, algumas modificações foram realizadas no instrumento inicial, sendo que o instrumento final obtido foi considerado fundamental à assistência do paciente na recuperação anestésica, classificando-o como completo, permitindo um fluxo de comunicação escrita e favorecendo a continuidade do processo de assistência de enfermagem ao paciente cirúrgico no pós-operatório.

Por outro lado, Cerqueira, citada por Cianciarullo ${ }^{(71)}$ enfatiza que: em nosso país, a maioria dos enfermeiros avalia empiricamente os cuidados prestados aos pacientes e os parâmetros destes cuidados são aceitos pela tradição, sendo transmitidos por meio de informação verbal. Ela ressalta que o desenvolvimento do processo de enfermagem, o estabelecimento de padrões de cuidados e a avaliação, por meio de 
processo de auditoria, não são comuns ainda, nos serviços de enfermagem, mas uma meta a ser atingida.

A informação é um requisito essencial para a prestação da assistência e gestão eficazes na atenção à saúde. O registro clínico no prontuário é o principal veículo de comunicação de informações sobre o paciente entre os membros da equipe multiprofissional de saúde e uma ferramenta importante para avaliação da qualidade dos serviços de saúde. Para tanto, deve conter as observações sobre a situação do paciente, as intervenções realizadas e os resultados obtidos ${ }^{(58)}$.

Apesar de vários estudos demonstrarem a vulnerabilidade em que o paciente se encontra no período pós-operatório imediato e a importância do instrumento de registro neste período, constata-se que muitos enfermeiros ainda deixam de consultar esse instrumento (Tabela 5), avaliando o paciente no momento da admissão (Tabela 7), utilizando-se de dados clínicos não padronizados (Quadro I). Estas constatações podem acarretar em não atendimento das necessidades do paciente, o que implicaria no surgimento de possíveis complicações associadas a sua patologia ou ao procedimento cirúrgico realizado.

Segundo Suarez ${ }^{(72)}$, a anotação é uma dentre as formas mais importantes de comunicação entre toda a equipe multiprofissional, colaborando para a promoção de uma assistência integral e qualificada.

A quantidade, e principalmente, a qualidade das anotações de enfermagem despertam em outros profissionais da equipe multiprofissional o interesse e a necessidade de consultá-las. Para a equipe médica, as anotações são meios valiosos de informações, fornecem bases para direcionar a terapêutica, os cuidados, a realização de novos diagnósticos. As anotações de enfermagem, cientificamente estruturadas, oferecem subsídios valiosos para o diagnóstico das 
necessidades de enfermagem, do paciente, da família e da comunidade. Elas favorecem também o planejamento da assistência a ser prestada e trazem elementos para o ensino e pesquisa no campo profissional.

Considerando as anotações de enfermagem como "o registro sistematizado, elaborado pela equipe de enfermagem no prontuário do paciente, do tratamento, das alterações subjetivas ou objetivas observadas, ou referidas pelo paciente, ou acompanhante" ${ }^{(71)}$, existe a necessidade de refletir seriamente, visando às mudanças urgentes nessa documentação legal e técnica comprobatória dos cuidados prestados pela equipe de enfermagem. Considerando ainda que as anotações de enfermagem expressam a assistência prestada ao cliente, nesse sentido, portanto, sugere-se que o enfermeiro atue frente a sua equipe de modo a conscientizá-la da importância da comunicação escrita a fim de procederem adequadamente às anotações.

Através da análise dos dados obtidos neste estudo, ficou demonstrado que, em ambos os hospitais, existem dificuldades na obtenção dos dados clínicos do paciente referente ao período de recuperação pós-anestésica relacionadas à comunicação escrita ou verbal. Observa-se, porém, que no Hospital II, onde o SAE já se encontrava implantado, a maioria dos enfermeiros $21(63,64 \%)$ planejavam o cuidado baseando-se nos dados clínicos contidos no instrumento de registro pertinente a esse período (Tabela 5). Embora esses registros se apresentassem incompletos, sem informações necessárias e, muitas vezes, estivessem ausentes do prontuário (Tabela 2), eles foram considerados, mesmo assim, de extrema importância (Tabela 6). No Hospital I, onde o SAE encontrava-se em processo de implantação, vimos que a maioria $18(69,23 \%)$ planejavam o cuidado baseando-se 
em dados clínicos não padronizados, porém, os 8 enfermeiros $(30,77 \%)$, que o consultavam também consideram os dados clínicos contidos no mesmo de extrema importância, com exceção dos parâmetros referentes à temperatura e pulso que apresentaram diferenças de opinião quanto ao nível de importância (extremamente importante e muito importante) - Tabela 6.

Diante de tal fato, pode-se contar com a parceria da educação continuada, visando a realização de reciclagens periódicas sobre os instrumentos de anotações de enfermagem a fim de promover segurança para a equipe e para o paciente, além da anotação de enfermagem refletir o grau de preparo dos profissionais, favorecendo a continuidade do trabalho nos diferentes plantões e nas diferentes áreas de assistência na instituição.

Oguisso $^{(73)}$, em um estudo que analisa a questão das anotações de enfermagem sob as dimensões legais, civil e penal e ético-profissionais, constatou que vários autores, encontrados na literatura brasileira, lamentam a pouca consistência do conteúdo das anotações. A legislação do exercício profissional vigente não reforça a importância dessa atividade como parte integrante do processo de cuidar, mas, ao contrário, torna-a uma incumbência "para fins estatísticos". A crescente conscientização das pessoas sobre os seus direitos como usuários dos serviços de saúde é uma realidade. O novo Código Civil aplica pagamento de indenização àquele que, no exercício de sua atividade profissional (sem distinção de categoria ou nível de qualificação), por negligência, imprudência ou imperícia, causar dano ao paciente. Assim, é necessário que os enfermeiros, gerentes/coordenadores/diretores, seja por escrito ou por via eletrônica, instituam e 
mantenham o sistema mais adequado e de mais elevado padrão das anotações de enfermagem em seus serviços.

Levando-se em consideração o aspecto ético e legal da documentação, foi possível perceber, através dos comentários feitos pelos enfermeiros entrevistados, a preocupação com os meios de documentação sobre os dados clínicos do paciente cirúrgico, enfatizando a importância de um instrumento de registro na sala de recuperação pós-anestésica que seja completo quanto às informações contidas no mesmo. Eles referiram ainda, que esse instrumento associado à passagem de plantão por telefone seria o principal meio de se obter informações a respeito desse paciente.

No dia-a-dia, verificamos que as anotações de enfermagem, de modo geral, não são completas em relação ao cuidado integral que o paciente necessita e recebe, e não satisfazem os requisitos necessários para sua padronização. Acreditamos que essas falhas ocorram devido à falta de conscientização de seu valor pelo pessoal de enfermagem ${ }^{(74)}$.

Pesquisa realizada por Matsuda, Évora e Boan ${ }^{(75)}$, demonstrou que, embora os enfermeiros reconheçam a importância da assistência de enfermagem ser planejada e implementada com enfoque no cliente, destacam as dificuldades em efetivar essa estratégia devido à escassez de recursos humanos, à falta de incentivos da instituição e à falta de valorização pela equipe dos aspectos interacionais com o cliente, corroborando com os resultados obtidos neste estudo, visto que, além de constatar que os enfermeiros consideram o instrumento de registro utilizado em recuperação pós-anestésica importante para promover a continuidade da assistência de enfermagem ao paciente cirúrgico no período pós-operatório, aponta as 
dificuldades específicas, apresentadas pelos enfermeiros, para obtenção dos dados clínicos do paciente com alta da recuperação pós-anestésica.

Embora tenhamos que admitir que as dificuldades apontadas interferem na qualidade da assistência prestada, é nosso compromisso direcionar esforços para solucioná-las com vistas a oferecer um serviço mais eficiente e competitivo.

Silva e Pinheiro ${ }^{(76)}$ recomendam que o enfermeiro, como líder da equipe, deve rever seu papel de supervisor, que busca apurar e registrar falhas, punir os culpados, para aquele que busca descobrir e eliminar as causas das falhas, estimulando a participação do pessoal nas decisões e na melhoria contínua, desenvolvendo tecnicamente as pessoas da sua equipe.

Quanto mais consciência o funcionário tiver sobre a finalidade dos registros de enfermagem, mais ele a fará com riqueza de conteúdo, colaborando assim, efetivamente, para a elaboração de cuidados de enfermagem individualizados.

Silva ${ }^{(77)}$ descreveu que o controle da qualidade, embora entendido como último passo de um processo, constitui-se apenas um elo de uma cadeia que alimenta continuamente e impulsiona as organizações para o desenvolvimento, pela melhoria de seus processos e resultados.

A qualidade da assistência de enfermagem só será alcançada quando toda a equipe estiver preparada e compromissada com o desenvolvimento adequado de suas ações, considerando que o comportamento e o desempenho individual geram impactos diretos na qualidade dos serviços. Portanto, cada componente da equipe deverá ter a oportunidade de visualizar claramente as características e influência do seu desempenho para o alcance da qualidade ${ }^{(77,78)}$. 
Para isso, torna-se necessário refletirmos sobre a formação do enfermeiro, a fim de criar uma série de indagações, de questionamentos e de contradições que venham servir de estímulo e ponto de partida para novos estudos nessa área de formação profissional, que é tão abrangente e estimulante e que, certamente, é responsável pela qualidade do profissional Enfermeiro.

Ressalta-se, ainda, que o processo de melhoria da qualidade exige e supõe a liderança da alta direção, que deve criar e compartilhar a visão e a missão da empresa, fixar diretrizes, estabelecer o enfoque no cliente, definir valores e suscitar elevadas expectativas. Isto tudo ocorrerá somente se a diretoria estiver visivelmente envolvida e comprometida, inclusive na caracterização das dimensões éticas e sociais da instituição ${ }^{(79)}$.

Além disso, na implementação de novos processos de trabalho, os enfermeiros devem ser inseridos desde o planejamento, a fim de garantir a implantação e sustentação dos mesmos. Gestão participativa implica em distribuir as responsabilidades e, ao mesmo tempo, dar voz aos indivíduos da organização ${ }^{(79,80,81)}$.

Este fator, associado à atuação da educação continuada, das instituições em estudo, deve ser levado em consideração para a análise da problemática de que as dificuldades na comunicação, referente ao paciente cirúrgico, estão interferindo na continuidade da assistência de enfermagem. 


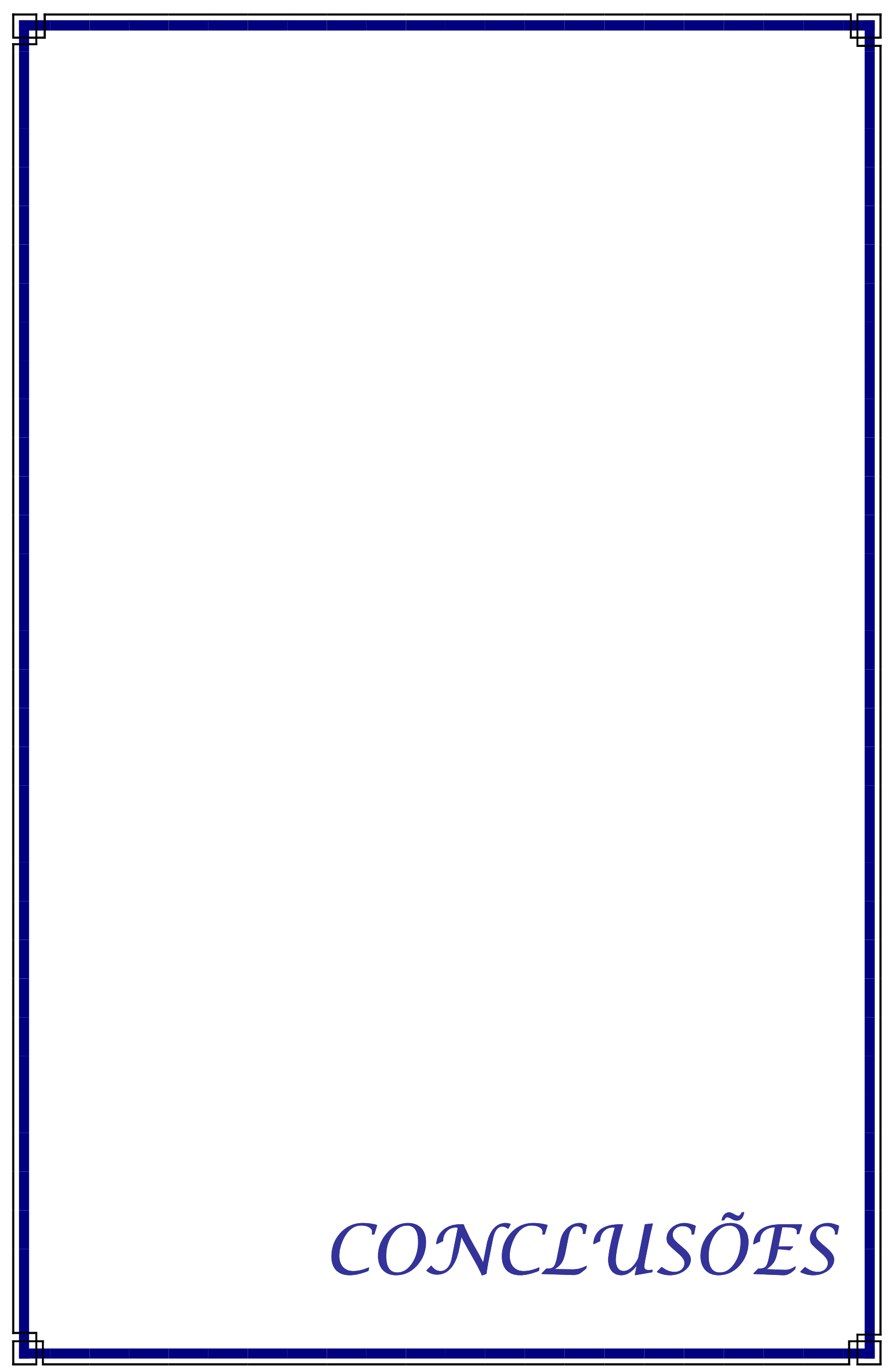




\section{CONCLUSÕES}

Os resultados levam as seguintes conclusões:

No Hospital I, as dificuldades mais freqüentes apresentadas, pelos enfermeiros, para obtenção dos dados clínicos do paciente, referente ao período de recuperação pós-anestésica foram: ausência, no prontuário, do instrumento utilizado na recuperação pós-anestésica; ausência da passagem de plantão por telefone, seguidas da falta de informações necessárias no instrumento; preenchimento incompleto do instrumento e passagem incompleta de plantão por telefone. Já, no Hospital II destacaram-se: preenchimento incompleto do instrumento, seguidas da falta de informações necessárias no instrumento; ausência, no prontuário, do instrumento utilizado na recuperação pós-anestésica; ausência da passagem de plantão por telefone e passagem incompleta de plantão por telefone.

No Hospital I, a melhor estratégia, citada pelos enfermeiros, para se obter informações do paciente, que recebe alta da recuperação pós-anestésica foi através de um instrumento de registro da recuperação pós-anestésica associado à passagem de plantão por telefone da enfermeira deste setor, enquanto que no Hospital II, os enfermeiros agregaram os diversos meios de se obter informações.

Dentre os dados clínicos considerados necessários, pelos enfermeiros que não consultavam o instrumento de registro da recuperação pós-anestésica, para planejar a assistência ao paciente cirúrgico, no Hospital I, destacaram-se: 
características dos curativos e drenos; nível de consciência; controle das sondas; sinais vitais e acesso venoso. No Hospital II, destacaram-se: sinais vitais e características dos drenos, seguidos de curativos; saturação de oxigênio e exame físico. Quanto aos enfermeiros que consultavam este registro, tanto do Hospital I quanto do Hospital II, verificou-se que a maioria classificou os dados clínicos, que deveriam estar presentes neste instrumento, como extremamente importante. Somente, no Hospital I, os parâmetros referentes à temperatura e pulso apresentaram diferenças de opinião quanto ao nível de importância (extremamente importante e muito importante).

Sendo assim observa-se, nos dois hospitais estudados, que o instrumento de registro, meio concreto de comunicação, auxilia no planejamento, promove a continuidade, é um indicador de qualidade, um meio de comunicação e um meio de documentar o cuidado. 


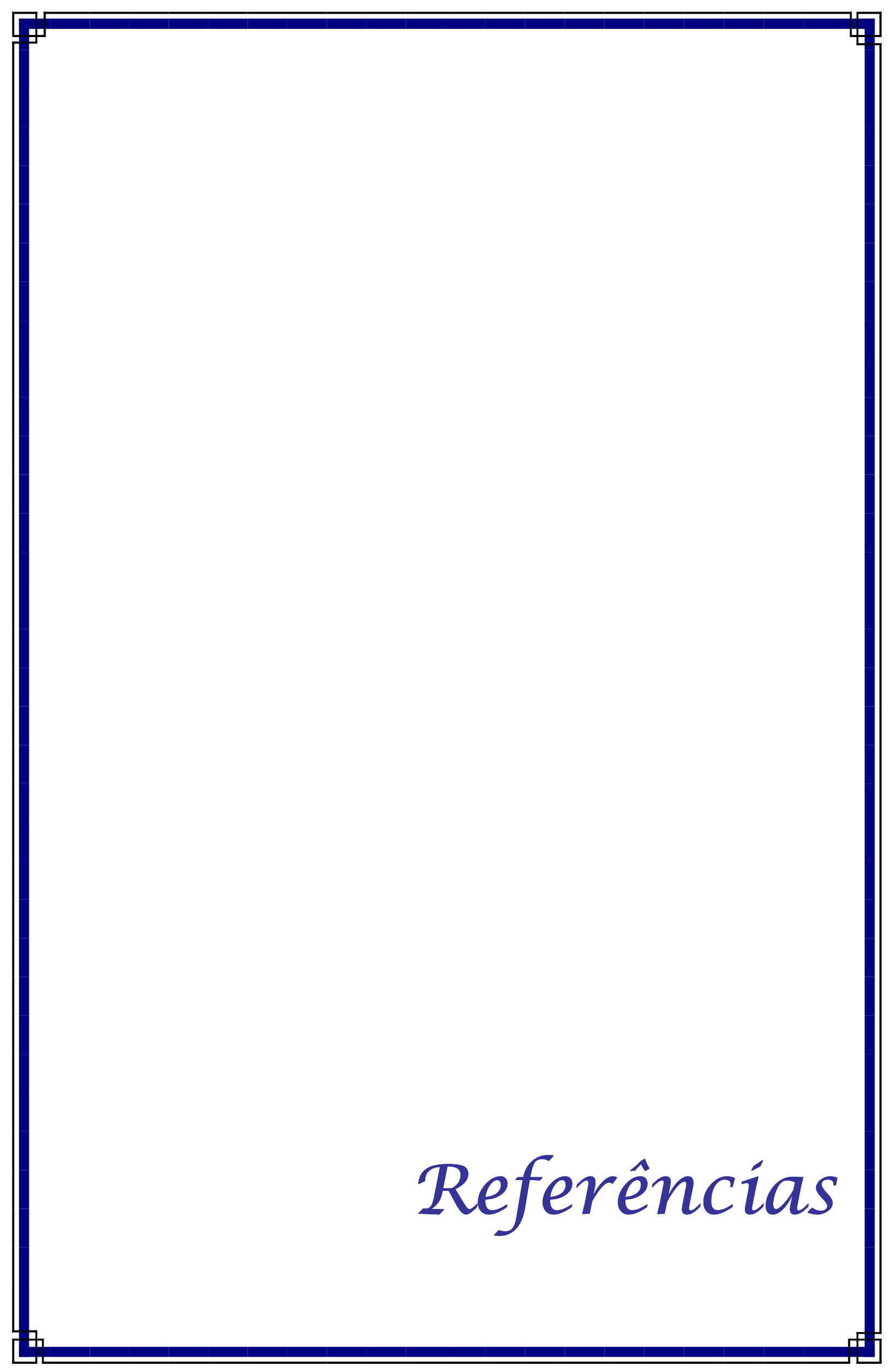




\section{Referências}

1. Conselho Regional de Enfermagem do Estado de São Paulo (COREN - SP). Decisão 008, de 19 de outubro de 1999 (DIR/ 008/1999). Normatiza a Implementação da Sistematização da Assistência de Enfermagem (SAE) nas Instituições de Saúde, no âmbito do Estado de São Paulo. São Paulo: COREN-SP;1999.

2. Miranda R. A prescrição de enfermagem como garantia de assistência com qualidade. Notícias Hospitalares. 2002;4(37):44-5.

3. Daniel LF.A enfermagem planejada. São Paulo: EPU/EDUSP;1979.

4. Padovani P, Gatto MAF, Peniche ACG. Ficha de recuperação anestésica: avaliação dos dados oferecidos para o planejamento da assistência de enfermagem no pós-operatório imediato. Enfoque. 1998;16(2):45-8.

5. Dell Acqua MCQ, Miyadahira AMK. Ensino do processo de enfermagem nas escolas de graduação em enfermagem do Estado de São Paulo. Rev Lat Am Enferm. 2002;10 (2):185-91.

6. Horta WA. O processo de enfermagem. São Paulo: EPU; 1979.

7. Mussi FC, Whitaker IY, Fernandes MFP, Gennari TD, Brasil VV, Cruz DALM. Processo de enfermagem: um convite à reflexão. Acta Paul Enferm. 1997;10(1):26-32.

8. Sena CA, Carvallho EC, Rossi LA, Ruffino MC. Rev Lat Am Enferm. 2001;9(1):27-38.

9. Iyer PW, Taptich BJ, Bernocchi-Losey D. Processo e diagnóstico em enfermagem. Porto Alegre: Artes Médicas; 1993.

10. Doenges ME, Moorhouse MF. Diagnóstico e intervenção em enfermagem. $5^{\mathrm{a}}$ ed. Porto Alegre: Artes Médicas; 1999.

11. Faria MCAD, Nobrega MML. Diagnósticos de enfermagem numa gestante de alto risco baseados na teoria de autocuidado de Orem: estudo de caso. Rev Lat Am Enferm. 2000;8(6):59-67.

12. Castellanos BEP. Aplicação do processo de enfermagem ao cuidado do paciente na unidade de centro cirúrgico. Rev Esc Enferm USP. 1978;12(3):170-86.

13. Horta W. A. O processo de enfermagem: fundamentação e aplicação. Enferm Novas Dimens. 1975;1(1):10-6.

14. Castellanos BEP. Aplicação do processo de enfermagem na unidade de centro cirúrgico. Rev Esc Enferm USP. 1978;12(3):170-86. 
15. Meeker MH, Rothroch JC. Alexander: cuidados ao paciente cirúrgico. $10^{\mathrm{a}}$ ed. Rio de Janeiro: Guanabara Koogan; 1997. Cuidados básicos de enfermagem perioperatória; p.3-17.

16. Christman L. Na all-RN or staff. AORN J. 1976;23(7):1194-7.

17. Fay MR. Nursing Process in the recovery room. AORN J. 1976;24(6):106975.

18. Mahomet AD. Nursing diagnosis for the OR nurse. AORN J. 1975;22(5):70911.

19. Miranda R. A prescrição de enfermagem como garantia de assistência com qualidade. Notícias Hospitalares. 2002;4(37):44-5.

20. Salzano SDT. Instrumento de comunicação de enfermagem: estudo da implantação de um modelo de comunicação escrita entre as equipes das unidades cirúrgicas e do centro cirúrgico. Rev Esc Enferm USP. 1983;17(3):235-52.

21. Teixeira J. O tão falado (e inobservável) prontuário do paciente. Notícias Hospitalares. 2002;4(39):54-55.

22. Jouclas VMG. Análise da função do circulante de sala de operações de acordo com a metodologia sistêmica de organização de recursos humanos [tese]. São Paulo (SP): Escola de Enfermagem, Universidade de São Paulo; 1987.

23. Brunner LS, Suddath DS. Tratado de enfermagem médico-cirúrgico. $7^{\mathrm{a}}$ ed. Rio de Janeiro: Guanabara; 1992. Assistência de enfermagem no perioperatório; p. 343-51.

24. Castellanos BEP, Bianchi ERF. Visita pré-operatória do enfermeiro da unidade de centro cirúrgico: marcos referenciais para o seu ensino no curso de graduação de enfermagem. Rev Paul Enferm. 1984;4(1):10-4.

25. Castellanos BEP, Jouclas VMG. Assistência de enfermagem perioperatória: um modelo conceitual. Rev Esc Enferm USP. 1990;24(3):359-70.

26. Salzano SDT. Estudo da variação de temperatura corpórea no paciente anestésico cirúrgico [tese]. São Paulo (SP): Escola de Enfermagem, Universidade de São Paulo; 1972.

27. Silva A. A visita pré-operatória de enfermagem pela enfermeira do centro cirúrgico. Rev Esc Enferm USP. 1987;21(2):145-60.

28. Silva MJP. Comunicação tem remédio: a comunicação nas relações interpessoais em saúde. São Paulo: Gente; 1996. 
29. Leite RCBO. A assistência de enfermagem perioperatória na visão do enfermeiro e do paciente cirúrgico idoso [tese]. São Paulo (SP): Escola de Enfermagem, Universidade de São Paulo; 2002.

30. Dalri MCB. Assistência de enfermagem a paciente portador de queimadura utilizando um software [tese]. Ribeirão Preto (SP): Escola de Enfermagem de Ribeirão Preto, Universidade de São Paulo; 2000.

31. Ferraz ER. Requisitos mínimos para a organização da sala de recuperação pós-anestésica e a assistência de enfermagem nela prestada. Rev Esc Enferm USP. 1980; 14(2):123-31.

32. Drain CB, Shipley SB. Enfermagem em sala de recuperação. Rio de Janeiro: Interamericana; 1981.

33. Barros MCD, Bartmann M, Hargreaves L. Enfermagem cirúrgica. Rio de Janeiro: SENAC/DN/DFP; 1996. p. 103-19.

34. Avelar MCQ, Peniche ACG, Paula TAC, Carbone NA, Silva RV. Validação dos padrões de assistência de enfermagem em recuperação anestésica. Rev Paul Enferm. 1991;10(n. esp):11-8.

35. Silva MD'A A, Rodrigues AL, Cezareti IUR. Enfermagem na Unidade de Centro Cirúrgico. $2^{a}$ ed. São Paulo: EPU; 1997. Estrutura organizacional da Sala de Recuperação Pós-Anestésica; p. 233-43.

36. Jouclas VMG. Elaboração e avaliação de um instrumento de comunicação que favoreça a assistência de enfermagem no transoperatório. [dissertação]. São Paulo (SP): Escola de Enfermagem, Universidade de São Paulo; 1977.

37. Peniche ACG. Abrangência da atuação do enfermeiro em sala de recuperação anestésica como perspectiva de melhor assistência ao paciente no período perioperatório. Rev Esc Enferm USP. 1995;29(1):83-90.

38. Anderson MA, Helms LB. Talking about patients: communication and continity of care. J cardiovasc Nurs. 2000;14(3):15-28.

39. Fávero N, Laus E, Nakao JRS, Évora YDM. A importância da comunicação como um instrumento administrativo: especial referência a anotação de enfermagem. Rev Paul Hosp. 1983;31(1/2) 4-7.

40. Matheus MCC, Bittes Junior A. Comunicação. In: Ciaciarullo TI. Instrumentos básicos para o cuidar: um desafio para a qualidade da assistência. São Paulo: Atheneu; 2000. p. 61-73.

41. Welter ER, Reiff PA. Transferring patiens from the OR: what the postanesthesia room nurses needs to know. AORN J. 1989;50(6):1248-52.

42. Hall LM, Doran D. Nurse staffing, care delivery model, and patient care quality. J Nurs Care Qual. 2004;19(1):27-33. 
43. Patterson PK, Blebm R, Foster J, Fuglee K, Moore J. Nurse information needs for efficient care continuity across patient units. JONA 1995; 25(10):29-36.

44. Potter PA, Perry AGP. Fundamento de enfermagem. $4^{\mathrm{a}}$ ed. Rio de Janeiro: Guanabara Koogan; 1999. Recuperação pós-operatória imediata; v. 2, p. 1298-302.

45. Lamond D. The information content of the nurse change of shift report: a comparative study. J Adv Nurs. 2000;31(4):794-804.

46. Posso MBS. Avaliação das condições dos pacientes na sala de recuperação pós-anestésica. Rev Esc Enferm USP. 1975;9(3):9-23.

47. Perez M, Cortez A, Mello FP, Oliveira GMS, Lima PGR, Amarante ST. Proposta de um instrumento para registro de ações de enfermagem perioperatória de um hospital privado. Rev Esc Enferm USP. 1991;10(ed. esp):33-41.

48. Kron T, Gray A. Administração dos cuidados de enfermagem ao paciente: colocando em ação as habilidades de liderança. Rio de Janeiro: Interlivros; 1994.

49. Teixeira MB, Prates JG, Almeida JG. Avaliação da qualidade das anotações de Enfermagem. HC Enferm. 1998; 2(2):8-10.

50. Zanon U. Qualidade da assistência de enfermagem médico-hospitalar: conceito e avaliação de indicadores. Rev Adm Saúde. 2000; 2(8):15-22.

51. Pádua AR. Análise das anotações de enfermagem: uma proposta de sistematização da assistência de enfermagem [dissertação]. São Paulo (SP): Departamento de Enfermagem, Universidade Federal de São Paulo; 2000.

52. Fávero N. Estudo das anotações de enfermagem na assistência direta ao paciente [dissertação]. Ribeirão Preto (SP): Escola de Enfermagem de Ribeirão Preto, Universidade de São Paulo; 1979.

53. Dalri MCB, Rossi LA, Carvalho EC. Aspectos éticos e legais das anotações de enfermagem nos procedimebntos de doação de órgãos para transplantes. Rev Esc Enferm USP. 1999;33(3):224-30.

54. Johanson L, Dantas CC, Leite JL, Andrade M, Stipp C. Registro de enfermagem: sua importância no controle e prevenção da infecção relacionada a cateter venoso em clientes de HIV/AIDS. In: Programas e resumos do $8^{\circ}$ Simpósio Brasileiro de Comunicação em Enfermagem SIBRACEN; 2002; Ribeirão Preto: EERP; 2002. p.107.

55. Araújo BMO. Evento adverso no período transoperatório: condutas do enfermeiro [dissertação]. São Paulo (SP): Escola de Enfermagem, Universidade de São Paulo; 2005. 
56. Labadia LL, Adami NP. Avaliação das anotações de enfermagem em prontuários de um hospital universitário. Acta Paul Enferm. 2004;17(1):55-9.

57. Janúncio IM. Análise das anotações de enfermagem no período perioperatório: subsídios para a continuidade da assistência prestada a pacientes de cirurgia cardíaca [dissertação] São Paulo (SP): Escola de Enfermagem, Universidade de São Paulo; 2002.

58. Pan American Health Organization (PAHO). Building standard: based nursing information systems. Washington, DC; c2001.

59. Kurcgant P. Administração em enfermagem. São Paulo: EPU; 1991

60. Takahashi RT. Sistema de informação em enfermagem. São Paulo: EPU; 1991. Administração em enfermagem; cap. 14, p. 181-9.

61. Daniel LF. Atitudes interpessoais em enfermagem. São Paulo: EPU; 1983.

62. Magalhães AM, Pires CS, Keretzky KB. Opinião de enfermeiros sobre a passagem de plantão. Rev Gaúcha Enferm. 1997;18(1):43-53.

63. Andrade JS, Vieira MJ, Santana MA, Lima DM. A comunicação entre enfermeiros na passagem de plantão. Acta Paul Enferm. 2004;17(3):311-5.

64. Nogueira RP. Perspectivas da qualidade em saúde. Rio de Janeiro: Qualitymark; 1994. Introdução às questões da qualidade na perspectiva dos serviços de saúde; cap.1, p. 17-7.

65. Monte ADAS, Adami NP, Barros ALBL. Métodos Avaliativos da Assistência de Enfermagem em Instituições Hospitalares. Acta Paul Enferm. 2001;14(1):89-97.

66. Haddad MCL. Qualidade da assistência de enfermagem: o processo de avaliação em hospital universitário público [tese]. Ribeirão Preto (SP): Escola de Enfermagem de Ribeirão Preto, Universidade de São Paulo; 2004.

67. Steward DJ. A simplified scoring system for the pos-operative recovery room. Can Anaesth Soc J. 1975;22:111-3.

68. Castãnos CC. Índices de recuperação. Rev Bras Anestesiol. 1982;32(6):4412.

69. Peniche ACG, Avelar MCQ, Rodrigues PG. Ficha de registro em sala de recuperação pós-anestésica: utilização após reestruturação. Rev Paul Enferm. 1991;10(ed. esp): 25-8.

70. Cunha ALCM. Análise do instrumento de registro da assistência de enfermagem em sala de recuperação anestésica [dissertação] São Paulo (SP): Escola de Enfermagem, Universidade de São Paulo; 2005. 
71. Cianciarullo TI. C\&Q: teoria e prática em auditoria de cuidados. São Paulo: Ícone; 1997. Controle de qualidade na assistência de enfermagem; cap. 2, p. 21-8.

72. Suarez GG. Anotações de enfermagem: padronização no Hospital de Clínicas da UFPR. Cogitare Enferm. 2000;5(n. esp):12-5.

73. Oguisso T. Dimensões ético-legais das anotações de enfermagem no prontuário do paciente. Rev Paul Enferm. 2003;22(3):245-54.

74. Fávero N, Trevizan MA, Mendes IAC. Atividades de assistência direta do enfermeiro e respectiva anotação. Enferm Atual. 1980;3(14):14-6.

75. Matsuda LM, Évora YDM, Boan FS. O foco no cliente no processo de atendimento de enfermagem: visão dos enfermeiros. Nursing. 2000;3(29):1620. [edição brasileira].

76. Silva MJP, Pinheiro EM. Qualidade na assistência de enfermagem de alunas de especialização. Acta Paul Enferm. 2001;14(1):82-8.

77. Silva SH. Controle da qualidade de enfermagem: implementação de um modelo [tese]. São Paulo (SP): Escola de Enfermagem, Universidade de São Paulo; 1994.

78. Padilha MICS. A qualidade total como recurso para a avaliação de enfermagem. Rev Hosp Adm Saúde. 1994;18(5):275-9.

79. Mezomo JC. Gestão da qualidade na saúde: princípios básicos. São Paulo: Manole; 2001.

80. Malik AM, Schiesari LM. Qualidade na gestão local de serviços e ações de saúde. São Paulo: FSP/USP; 1998.

81. Antunes AV. Liderança para a qualidade na enfermagem. Nursing. 1999;2(15):22-6. [edição brasileira]. 


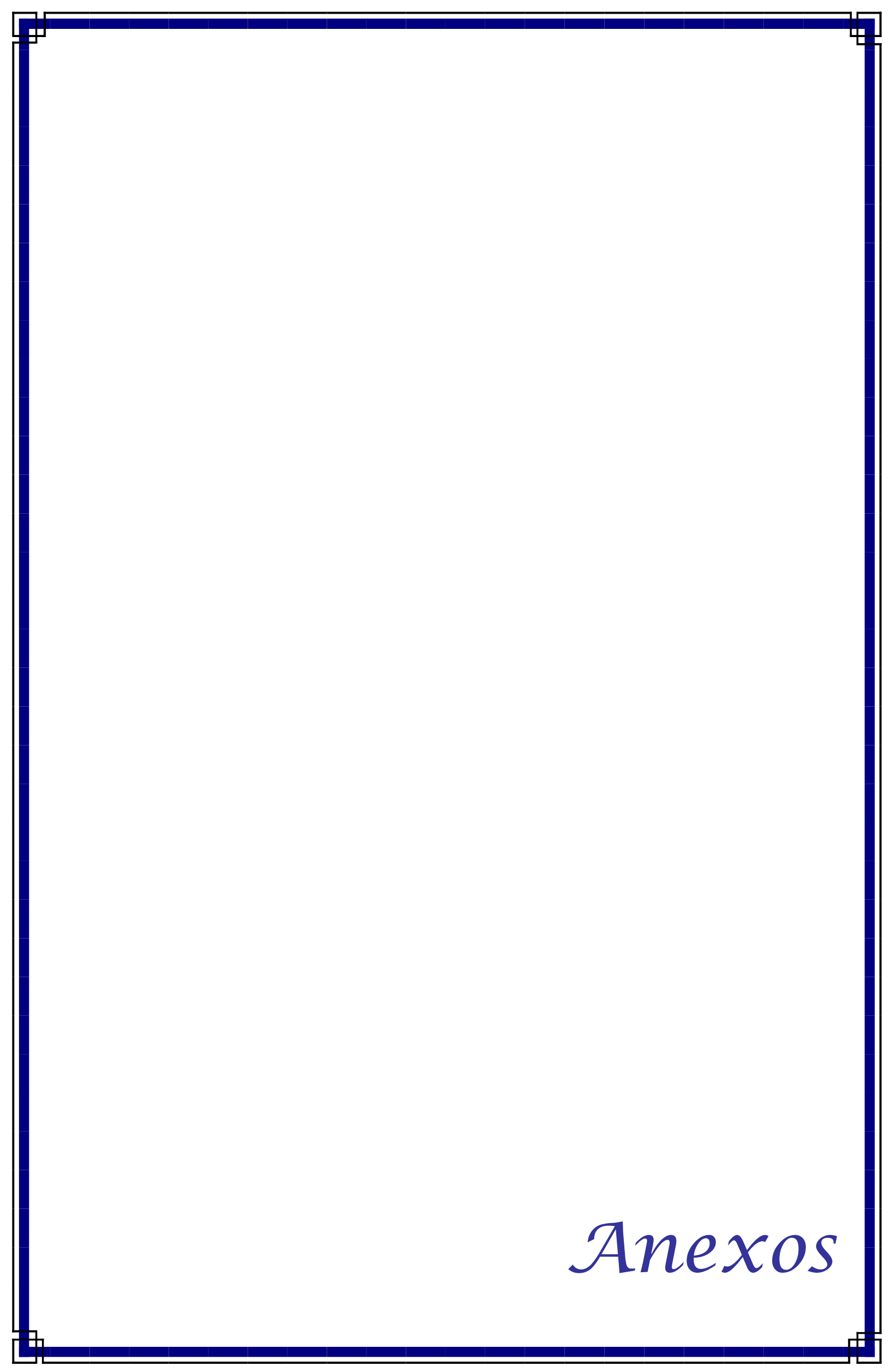




\section{ANEXO A}

Avaliação do Instrumento de Registro em Sala de Recuperação Pós-Anestésica

\section{Parte I- Perfil do enfermeiro}

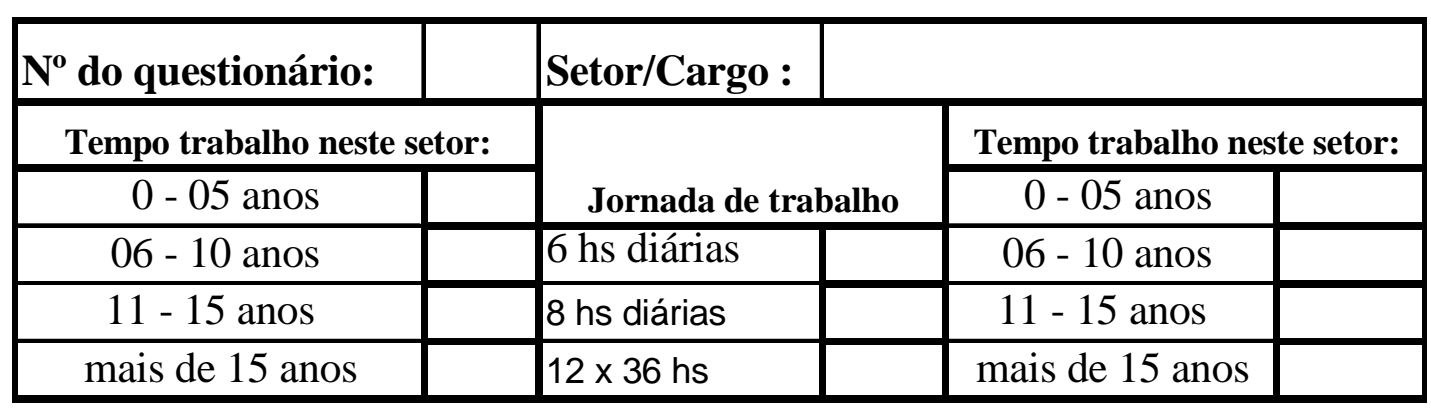

\begin{tabular}{|l|l|}
\hline \multicolumn{2}{|c|}{ Cursos de especialização ou outros: } \\
\hline enfermagem médico-cirúrgica & \\
\hline enfermagem cirúrgica & \\
\hline enfermagem em centro cirúrgico & \\
\hline enfermagem em UTI & \\
\hline enfermagem em pronto socorro & \\
\hline enfermagem oncológica & \\
\hline enfermagem em urologia/nefrologia & \\
\hline enfermagem em ginecologia/ obstetrícia & \\
\hline administração em enfermagem & \\
\hline mestrado & \\
\hline doutorado & \\
\hline outros (especificar): & \\
\hline
\end{tabular}




\section{Parte II}

1) Com que freqüência as dificuldades, listadas abaixo, interferem na obtenção dos dados clínicos necessários para o planejamento da assistência ao paciente que recebe alta da sala de recuperação pós-anestésica?

$$
\begin{gathered}
5 \text { - sempre } \\
4 \text { - muitas vezes } \\
3 \text { - algumas vezes } \\
2 \text { - poucas vezes } \\
1 \text { - nunca ocorrem }
\end{gathered}
$$

0 - não tenho opinião/não sei/não se aplica

prontuários com ausência do instrumento

prontuários com o instrumento, porém preenchido incompletamente

o instrumento não contém todas as informações que considero importante

ausência da passagem de plantão por telefone

passagem de plantão por telefone incompleta

outras dificuldades (especificar): 
2) Qual a melhor estratégia para receber as informações necessárias para a continuidade da assistência ao paciente cirúrgico após a alta da sala de recuperação pós anestésica?

a) por um instrumento da sala de recuperação pós-anestésica que contenha todas as informações necessárias

b) passagem de plantão por telefone da enfermeira da recuperação pós-anestésica

c) passagem de plantão pelo funcionário que transporta o paciente para a clínica cirúrgica

d) sistema informatizado

e) nenhuma informação é necessária

f) através da associação de $\mathrm{a} e \mathrm{~b}$

g) outros meios (especificar):

3) Sendo o instrumento de registro um meio concreto de comunicação, como você o avalia de acordo com a escala de nível de importância:

5 - concordo plenamente

4 - concordo parcialmente

3 - não tenho opinião/não sei/não se aplica

2 - discordo parcialmente

1 - discordo plenamente

auxilia no planejamento do cuidado de enfermagem

promove a continuidade da assistência

é um indicador da qualidade da assistência

é um meio de comunicação eficaz

é um meio de documentar o cuidado prestado

outras dificuldades (especificar): 
4) Você consulta os dados clínicos contidos no instrumento de registro da sala de recuperação pós-anestésica para planejar o cuidado do paciente?

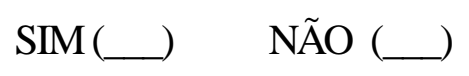

4a) Se sim, avalie os dados clínicos, listados abaixo, de acordo com a escala de nível de importância:

5- extremamente importante 4- muito importante 3- medianamente importante

2- pouco important e 1- nada importante 0- não tenho opinião/não sei/não se aplica

Cirurgia

Anestesia

Temperatura

Pulso

Respiração

Pressão arterial

Saturação de oxigênio

Nível de consciência

Atividade

Coloração

Curativos (locais e aspecto)

Drenos

Cateteres

Sondas

Ostomias

Balanço hídrico

Medicações utilizadas

Intercorrências

Outros (especificar):

4b) Se não, qual o motivo?

\begin{tabular}{|l|l|}
\hline falta de tempo & \\
\hline cópia ilegível & \\
\hline informações não compreensíveis & \\
\hline não precisa das informações da recuperação pós-anestésica & \\
\hline instrumento complicado & \\
\hline $\begin{array}{l}\text { avalio o paciente no momento da admissão (especificar os dados clínicos que } \\
\text { utiliza): }\end{array}$ & \\
\hline outros motivos (especificar): & \\
\hline
\end{tabular}




\section{ANEXO B \\ Termo de Consentimento Livre e Esclarecido}

Instrumento de registro utilizado na avaliação em sala de recuperação pósanestésica: importância na continuidade da assistência ao paciente cirúrgico

\section{Pesquisadora: Elaine Reda}

RG: 21.851.823-7

R: Tobias Franco, 289 - Centro - Itatiba/SP

Fone: (11) 9118-7512/4538-4767

Orientadora: Prof ${ }^{\mathrm{a}}$ Dr $^{\mathrm{a}}$ Aparecida de Cássia Giani Peniche

\section{O abaixo assinado:}

Nome:

Endereço:

Cidade/ Estado:

RG:

Idade:

declara que é de livre e espontânea vontade que está participando como voluntário do projeto de pesquisa supra-citado, de responsabilidade do pesquisador. O voluntário está ciente que:

I. Os objetivos desta pesquisa são:

\section{Objetivo geral:}

Conhecer a avaliação feita, pelos enfermeiros das unidades pósoperatórias, a respeito da continuidade da assistência de enfermagem ao paciente cirúrgico. 


\section{Objetivos específicos:}

- Identificar as dificuldades apresentadas pelos enfermeiros na obtenção dos dados clínicos referentes ao período de recuperação pósanestésica.

- Identificar a melhor estratégia para receber os dados clínicos necessários para a continuidade da assistência de enfermagem ao paciente cirúrgico, após receber alta da sala de recuperação pósanestésica.

- Identificar os dados clínicos, referentes ao período de recuperação pós-anestésica, considerados necessários para o planejamento da assistência de enfermagem no período pós-operatório.

II. Será realizado um estudo descritivo, exploratório, de campo, a partir de um instrumento de coleta de dados, a fim de contemplar os objetivos deste estudo.

III. A participação neste estudo não acarretará nenhum risco que possa comprometer a garantia de trabalho como profissional enfermeiro.

IV. Obteve todas as informações necessárias para poder decidir conscientemente sobre a participação do referido estudo.

V. Está livre para interromper a participação no estudo a qualquer momento ou deixar de responder qualquer pergunta.

VI. A interrupção do estudo não lhe causará prejuízo, tanto pessoal quanto profissional, diante a supervisão da instituição a qual pertence. 
VII. Responderá a um formulário, o qual não possuirá nenhuma forma de fornecer sua identidade, visto que todas as informações obtidas serão convertidas em dados numéricos.

VIII. Uma vez encerrado o trabalho, os resultados poderão ser divulgados em eventos e revistas científicas, onde será mantido sigilo e anonimato de qualquer informação por ele fornecida.

IX. Poderá contactar a pesquisadora, sempre que necessário, pelo telefone supracitado.

X. Poderá contactar o Comitê de Ética em Pesquisa para apresentar recursos ou reclamações em relação ao estudo (Fones: (11) 4034-8028 - Comitê de Ética em Pesquisa - USF e (19) 3788-8936 - Comitê de Ética em Pesquisa - FCM UNICAMP).

XI. Não será ressarcido pelo tempo dispendido durante o estudo em R \$.

XII. Este Termo de Consentimento, livre e esclarecido, constará de duas vias, sendo uma delas entregue ao voluntário.

São Paulo, de de 2005.

Assinatura do voluntário:

Responsável: Elaine Reda

Assinatura: 


\section{ANEXO C}

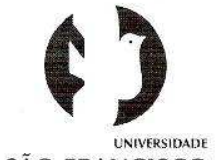

SÃO FRANCISCO

Bragança Paulista, 28 de junho de 2004

\section{COMITÊ DE ÉTICA EM PESQUISA - USF}

Projeto de Pesquisa: "Continuidade da assistência de enfermagem no período pósoperatório imediato: Análise dos dados clínicos"

Autores: Profa. Elaine Reda

Protocolo $n^{\circ}$. CEP/CBS $-68 / 04$

Prezada Profa.,

O Comitê de Ética em Pesquisa da Área de Ciências Biológicas e da Saúde da Universidade São Francisco, analisou as Pendência s esclarecidas referente ao projeto de pesquisa supra-citado, sob a responsabilidade de V.Sa.. Este Comitê, acatando o parecer do relator indicado, apresenta-Ihe o seguinte resultado:

Parecer: Aprovado

Atenciosamente,

Prof. Dr. José Pedrazzoli Júnior

Coordenador do Comitê de Ética em Pesquisa

Área de Ciências Biológicas e da Saúde

Universidade São Francisco 


\section{ANEXO D}

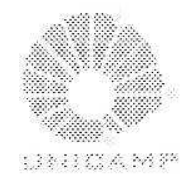

FACULDADE DE CIÊNCIAS MÉDICAS

COMITÊ DE ÉTICA EM PESQUISA

$\triangle$ Caixa Postal 6111, 13083-970 Campinas, SP

둘 $(0$ 19) $3788-8936$

FAX (0_19) 3788-8925

Www.fcm.unicamp. br/pesquisa/etica/index.htm.

므 cep a fom.unicamp.br

CEP, 24/05/05.

(Grupo III)

PARECER PROJETO: $N^{\circ} 076 / 2005$

\section{I-IDENTIFICAÇÃO:}

PROJETO: "IMPORTÂNCIA DO INSTRUMENTO DE AVALIAÇÃO EM SALA DE RECUPERAÇÃO ANESTÉSICA NA PERCEPÇÃO DO ENFERMEIRO"

PESQUISADOR RESPONSÁVEL: Elaine Reda

INSTITUIÇÃO: Hospital Estadual Sumaré

APRESENTAÇÃO AO CEP: 03/03/2005

APRESENTAR RELATÓRIO EM: 24/05/06

\section{II - OBJETIVOS}

Conhecer a opinião dos enfermeiros sobre a importância dos instrumentos de registro na continuidade da assistência de enfermagem aos pacientes cirúrgicos no período pós-operatório

\section{III - SUMÁRIO}

Serão entrevistados enfermeiros do centro cirúrgico de dois hospitais públicos de São Paulo, um com a sistematização da assistência de enfermagem já completamente implantada e outro em implantação. Os dados serão comparados e serão analisadas as semelhanças e diferenças entre os hospitais.

\section{IV - COMENTÁRIOS DOS RELATORES}

O projeto tem baixo risco para os sujeitos da pesquisa, já que se trata de resposta a questionário e entrevista. O Termo de Consentimento Livre e Esclarecido está completo e claro.

\section{V - PARECER DO CEP}

O Comitê de Ética em Pesquisa da Faculdade de Ciências Médicas da UNICAMP, após acatar os pareceres dos membros-relatores previamente designados para o presente caso e atendendo todos os dispositivos das Resoluções 196/96 e complementares, bem como ter aprovado o Termo do Consentimento Livre e Esclarecido, assim como todos os anexos incluidos na Pesquisa, resolve aprovar sem restrições o Protocolo de Pesquisa supracitado.

O conteúdo e as conclusões aqui apresentados são de responsabilidade exclusiva do CEP/FCM/UNICAMP e não representam a opinião da Universidade Estadual de Campinas nem a comprometem. 


\title{
VI - INFORMAÇÕES COMPLEMENTARES
}

O sujeito da pesquisa tem a liberdade de recusar-se a participar ou de retirar seu consentimento em qualquer fase da pesquisa, sem penalização alguma e sem prejuízo ao seu cuidado (Res. CNS 196/96 - Item IV.1.f) e deve receber uma cópia do Termo de Consentimento Livre e Esclarecido, na integra, por ele assinado (Item IV.2.d).

Pesquisador deve desenvolver a pesquisa conforme delineada no protocolo aprovado e descontinuar o estudo somente após análise das razões da descontinuidade pelo CEP que o aprovou (Res. CNS Item III.1.z), exceto quando perceber risco ou dano não previsto ao sujeito participante ou quando constatar a superioridade do regime oferecido a um dos grupos de pesquisa (Item V.3.).

O CEP deve ser informado de todos os efeitos adversos ou fatos relevantes que alterem 0 curso normal do estudo (Res. CNS Item V.4.). É papel do pesquisador assegurar medidas imediatas adequadas frente a evento adverso grave ocorrido (mesmo que tenha sido em outro centro) e enviar notificação ao CEP e à Agência Nacional de Vigilância Sanitária - ANVISA junto com seu posicionamento.

Eventuais modificações ou emendas ao protocolo devem ser apresentadas ao CEP de forma clara e sucinta, identificando a parte do protocolo a ser modificada e suas justificativas. Em caso de projeto do Grupo I ou II apresentados anteriormente à ANVISA, o pesquisador ou patrocinador deve enviá-las também à mesma junto com o parecer aprovatório do CEP, para serem juntadas ao protocolo inicial (Res. 251/97, Item III.2.e)

Relatórios parciais e final devem ser apresentados ao CEP, de acordo com os prazos estabelecidos na Resolução CNS-MS 196/96.

\section{VII - DATA DA REUNIÃO}

Homologado na V Reunião Ordinária do CEP/FCM, em 24 de maio de 2005.

\author{
Chtwen \\ Profa. Dra. Carmen Sílvia Bertuzzo \\ PRESIDENTE DO COMITÊ DE ÉTICA EM PESQUISA \\ FCM / UNICAMP
}

